\title{
DOES MARIJUANA LEGALIZATION AFFECT WORK CAPACITY? EVIDENCE FROM WORKERS' COMPENSATION BENEFITS
}

\author{
Rahi Abouk \\ Keshar M. Ghimire \\ Johanna Catherine Maclean \\ David Powell \\ Working Paper 28471 \\ http://www.nber.org/papers/w28471 \\ NATIONAL BUREAU OF ECONOMIC RESEARCH \\ 1050 Massachusetts Avenue \\ Cambridge, MA 02138 \\ February 2021
}

Authors listed in alphabetical order. All authors contributed equally to the manuscript. Powell gratefully acknowledges funding from NIDA (P50DA046351). We thank seminar participants at Indiana University and the Workers' Compensation Research Institute for helpful feedback. We also thank Alex Hollingsworth, Melissa McInerney, John Mullahy, Sarah Stith, and Shyam Raman for helpful comments. The views expressed herein are those of the authors and do not necessarily reflect the views of the National Bureau of Economic Research.

NBER working papers are circulated for discussion and comment purposes. They have not been peer-reviewed or been subject to the review by the NBER Board of Directors that accompanies official NBER publications.

(C) 2021 by Rahi Abouk, Keshar M. Ghimire, Johanna Catherine Maclean, and David Powell. All rights reserved. Short sections of text, not to exceed two paragraphs, may be quoted without explicit permission provided that full credit, including $\odot$ notice, is given to the source. 
Does Marijuana Legalization Affect Work Capacity? Evidence from Workers' Compensation Benefits

Rahi Abouk, Keshar M. Ghimire, Johanna Catherine Maclean, and David Powell

NBER Working Paper No. 28471

February 2021

JEL No. H12,I12,I18,J32

\section{ABSTRACT}

We study the effect of state recreational marijuana laws (RMLs) on workers' compensation (WC) benefit receipt among adults 40-62 years. We find that WC receipt declines in response to RML adoption both in terms of the propensity to receive benefits and benefit amount. We estimate complementary declines in non-traumatic workplace injury rates and the incidence of worklimiting disabilities. We offer evidence that the primary driver of these reductions is an improvement in work capacity, likely due to access to an additional form of pain management therapy.

\author{
Rahi Abouk \\ William Paterson University \\ Department of Economics, Finance, \\ and Global Business \\ 300 Pompton Road \\ Wayne, NJ 07470 \\ aboukr@wpunj.edu \\ Keshar M. Ghimire \\ Business and Economics Department \\ University of Cincinnati - Blue Ash \\ 9555 Plainfield Road \\ Blue Ash, OH 45236 \\ USA \\ ghimirkr@ucmail.uc.edu
}

Johanna Catherine Maclean

Department of Economics

Temple University

Ritter Annex 869

Philadelphia, PA 19122

and NBER

catherine.maclean@temple.edu

David Powell

RAND Corporation

1776 Main Street

P.O. Box 2138

Santa Monica, CA 90407

dpowell@rand.org 


\section{Introduction}

Marijuana has increasingly become legalized in the United States. We study the effects of recent state laws that legalize the recreational use of marijuana on work capacity - the ability to productively engage in paid employment - among older working-age adults. We rely primarily on Workers' Compensation (WC) benefit receipt as a signal of diminished work capacity; WC benefits are received when individuals become injured or ill while working and require time away from work to recover. In addition to providing a useful measure of labor productivity and work capacity, injuries incurred while working represent substantial costs to the national economy (Leigh 2011).

Most of the costs of workplace injuries are borne by workers and their families. The WC program is designed specifically to transfer some of these costs from workers and families to governments and firms. In 2018, WC cash and medical payments to workers totaled $\$ 62.9$ billion (Weiss, Murphy, and Boden 2020), equivalent to the size of annual Earned Income Tax Credit expenditures. The economic literature on WC to date typically focuses on the impacts of the incentives inherent in the system on injury duration (e.g., Meyer, Viscusi, and Durbin (1995); Neuhauser and Raphael (2004); and Cabral and Dillender (2020)) or the program's consumption smoothing benefits (Bronchetti 2012). There is less evidence on the impact of policies not directly targeting WC to affect costs and benefit receipt. ${ }^{1}$

The continued legalization of marijuana in the U.S. has been controversial, including its potential to harm the productivity of the workforce. ${ }^{2}$ Due to the product's medicinal properties,

\footnotetext{
${ }^{1}$ One exception is a small literature on the impacts of access to health insurance on WC claiming behavior (e.g., Bronchetti and McInerney (2017); Lakdawalla, Reville, and Seabury (2007); and Dillender (2015)). Further, Ohsfeldt and Morrisey (1997) study the effect of beer taxes on WC and workplace injuries.

${ }^{2}$ See discussions in National Institute on Drug Abuse (2020) and https://www.usnews.com/news/beststates/articles/2018-08-01/the-legalization-of-recreational-marijuana-an-economic-opportunity-for-states (last accessed January 27, 2021).
} 
states initially passed medical marijuana laws (MMLs), providing legal protection for individuals with specific health conditions to use this product to treat symptoms associated with ailments. ${ }^{3}$ California was the first state, in 1996, to adopt an MML. By December 2020, 33 states and the District of Columbia had adopted such law (ProCon.org 2020a). Following the wave of MML adoption, states have recently passed laws that legalize marijuana for recreational use ('RMLs'). The initial RMLs were adopted in 2012 when Colorado and Washington legalized recreational marijuana use for adults 21 and older. As of December 2020, marijuana use is legal for recreational purposes in 16 states and the District of Columbia with five additional states officially announcing that they will adopt such a policy in the future (ProCon.org 2020b).

Critics argue that legalization of marijuana will lead to greater addiction, crime, healthcare costs, and other social ills within the population while harming health and labor market outcomes. ${ }^{4}$ However, marijuana legalization is popular among Americans: in 2019, 67\% supported legalization for recreational use, and $91 \%$ supported legalization for recreational or medical use (Daniller 2019). Despite popular support and legislative efforts by some lawmakers (e.g., the Marijuana Opportunity Reinvestment and Expungement [MORE] Act of 2019), ${ }^{5}$ marijuana use has been prohibited federally since the Marihuana Act of 1937, leading to a direct conflict between state and federal law.

A small literature has considered the labor supply consequences, with a focus on older working-age adults, of the availability of pain management therapies (Garthwaite 2012; Bütikofer and Skira 2018). In this paper, we use RML adoption as a large shock to the

\footnotetext{
${ }^{3}$ Marijuana is not likely to improve health per se, but rather use of this product may allow better management of symptoms associated with chronic and acute conditions.

${ }^{4}$ See for example https://marijuana.procon.org/ and https:/www.haylor.com/wp-content/uploads/2014/05/AssurexMarijuana-White-Paper.pdf (all websites last accessed January 27, 2021).

${ }^{5}$ This Act, while not successful to date, proposes to decriminalize marijuana possession. The Act does not go as far as legalization, either for medical or recreational purposes, but would reflect a profound shift in U.S. federal law.
} 
availability of an alternative form of chronic pain management, in particular one that does not require a prescription or a consultation with a healthcare professional but may pose other concerns such as stigma, issues related to drug testing at work, and so forth. There is significant policy interest in understanding and improving the work capacity of older adults in the U.S., especially given its implications for social insurance programs (Coile, Milligan, and Wise 2017; Cutler, Meara, and Richards-Shubik 2013; Lopez-Garcia, Maestas, and Mullen 2019).

We study WC as an important metric of work capacity for this population and due to independent policy interest in the determinants of WC benefit receipt. While WC expenditures are high, they have recently been on a decline. Figure 1A depicts trends in WC real expenditures in the U.S. over the period 2010 to 2018. Of particular interest to our study, the most recent decline in WC costs began in 2012 (Weiss, Murphy, and Boden 2020), the first year in which a U.S. state adopted an RML.

There is limited - though growing - evidence on the work capacity implications of RMLs. These policies improve access to marijuana even beyond MMLs (Hollingsworth, Wing, and Bradford 2019; Cerdá et al. 2020), leading to reduced demand for other types of pain management therapies (Wen and Hockenberry 2018; McMichael, Van Horn, and Viscusi 2020; Chan, Burkhardt, and Flyr 2020; Carrieri, Madio, and Principe 2020). This evidence indicates that RMLs improve access to an additional channel for managing pain and other health conditions, suggesting potential benefits on populations at risk of workplace injuries. ${ }^{6}$ Many states include a relatively limited set of 'qualifying' health conditions in their MML; for example, Pennsylvania does not consider chronic pain, the most commonly reported reason for using medical marijuana (Park and Wu 2017; Kosiba, Maisto, and Ditre 2019), as a qualifying

\footnotetext{
${ }^{6}$ For example, $30 \%$ of all fatal and nonfatal occupational injuries and illnesses are due to musculoskeletal disorders, such as back pain, hernias, sprains, strains, and tears, alone (Bureau of Labor Statistics 2016).
} 
health condition. ${ }^{7}$ Additionally, healthcare providers working in Federally Qualified Health Centers must adhere to federal law and thus cannot recommend marijuana, even in states where medical use of this product is legalized.

In this study, we investigate the effect of state RMLs on WC receipt among adults ages 40 to 62 years of age ('older adults'). We study older adults since they are more likely to experience health conditions for which marijuana may be effective in symptom management and to use prescription medications for which marijuana may serve as a therapeutic substitute (Nicholas and Maclean 2019; Hales, Martin, and Gu 2020). Over the period 2015 to 2018, only $5.4 \%$ of adults 20 to 39 years reported use of a prescription pain medication in the past 30 days compared to $12.7 \%$ of adults 40 to 59 years and $15.1 \%$ of adults 60 years and older (Hales, Martin, and Gu 2020). Chronic pain prevalence is substantially higher among adults 45 to 64 years (Dahlhamer et al. 2018). ${ }^{8}$ At the same time, rates of marijuana misuse are lower among older (vs. younger) adults (see Table 1 in Choi, DiNitto, and Marti (2017)), suggesting that concerns regarding negative health and labor market implications associated with legalization may be muted for older adults.

We evaluate the effect of RMLs on WC benefit receipt and WC income over the period 2010 to 2018 using the Annual Social and Economic Supplement (ASEC) of the Current Population Survey (CPS). We also assess possible mechanisms explaining the changes in WC benefit receipt by studying marijuana use and misuse; use of therapeutic substitutes (medications used to treat chronic pain); and a broader set of work capacity measures including labor supply, workplace injury rates, self-assessed health, and the incidence of work-limiting disabilities.

\footnotetext{
${ }^{7}$ See, for example, https://filtermag.org/heres-how-infuriatingly-hard-it-still-is-to-get-medical-marijuana-in-newyork/ (last accessed January 27, 2021).

${ }^{8}$ Chronic pain is defined as pain on most days or every day in the past six months (Deyo et al. 2015).
} 
Our results show a decline in WC benefit propensity of 0.18 percentage points ('ppts'), which corresponds to a $20.0 \%$ reduction in any WC income, after states legalize marijuana for recreational use. Similarly, we find that annual income received from WC declines by $\$ 21.98$ (or 20.5\%) post-RML. These results are not driven by pre-existing trends, and falsification exercises suggest that observing estimates of this magnitude is statistically rare. While our estimated effect sizes are arguably large, the literature to date demonstrates substantial (20-38\%) increases in marijuana use post-RML (see Section 2.2). Previous economic research documents large changes in labor supply in response shocks to pain medication availability. Garthwaite (2012) documents a 10\% reduction in the probability of working following removal of one type of pain management therapy from the market ${ }^{9}$ while Bütikofer and Skira (2018) estimate 12$16 \%$ reductions in sickness absences following the removal of this treatment.

We find evidence that marijuana use, but not misuse, increases after RML adoption, which is in line with additional medical use among older adults. We also show that prescription fills for medications used to treat chronic pain decrease post-RML. The observed reduction in WC benefits is not due to a concurrent decrease in labor supply mechanically reducing WC participation or due to industry composition shifts which lead to a higher share of the workforce in safer industries. Instead, we observe an increase in labor supply due to RML adoption, which is further in line with RMLs improving work capacity among older adults (Ghimire and Maclean 2020; Nicholas and Maclean 2019). We observe complementary evidence that RMLs reduce (non-fatal) workplace injury rates and self-reported work-limiting disability propensities. These results suggest that RMLs reduce work limitations related to chronic health conditions.

\footnotetext{
${ }^{9}$ See page 125 of that paper.
} 
The paper proceeds as follows. Section 2 outlines WC programs in the U.S., mechanisms that may link RML adoption to WC benefit receipt, and related literature. Section 3 describes data and methods. The main results and sensitivity analyses are reported in Section 4. We consider possible mechanisms in Section 5 while heterogeneity is discussed in Section 6 . Finally, Section 7 concludes.

\section{Background}

\subsection{Workers' Compensation}

WC was one of the earliest social insurance programs in the U.S. This program was designed as a compromise to shield employers from tort liability, and to provide income and medical assistance to injured workers. Except for Texas, where employer participation in WC is optional (Cabral, Cui, and Dworsky 2019; Jinks et al. 2020), almost all wage and salary workers are covered by WC. Employers typically purchase WC coverage or self-insure to meet these obligations, though the costs of WC benefits, like many other mandated benefits, could be passed on to employees through reduced wage and non-wage compensation (Summers 1989; Gruber and Krueger 1991).

These programs represent a critical component of the social safety net as they offer financial protection to injured/ill workers. The Department of Labor, however, recently issued a report which ‘sounds an alarm' regarding deteriorating benefits in state WC programs (U.S. Department of Labor 2016). State attempts to reduce WC costs highlight increased policy demand for mechanisms to decrease injury rates and WC participation. ${ }^{10}$

While there are differences across states, most WC programs in the U.S. require employers to provide employees who become injured or ill while working with cash and medical

\footnotetext{
${ }^{10} \mathrm{We}$ note that these state actions could also contribute to the decline in WC expenditures documented in Figure $1 \mathrm{~A}$.
} 
benefits as the employee recovers. Employees unable to recover are evaluated for permanent disability benefits. The wage-replacement rate for WC is typically two-thirds of an employee's pre-injury/illness gross wage with minimum and maximum benefits levels varying by state (Weiss, Murphy, and Boden 2020). Benefits are offered to the employee regardless of fault, but covered employees are prohibited from suing the employer in relation to the injury or illness. ${ }^{11}$

\subsection{Related literature on marijuana legalization laws}

While there is a large literature on the effects of state MMLs, ${ }^{12}$ fewer studies have evaluated RML impacts given their recent adoption. In this section, we focus on studies examining RML effects and draw upon studies evaluating the effects of MMLs on particularly relevant outcomes to our study.

Several studies clearly establish that adult marijuana use increases post-RML, typically estimating very large effect sizes. Using national data from the NSDUH, a recent study shows that past-30 day marijuana use among adults increases by $28 \%$ following RML adoption (Cerdá et al. 2020). ${ }^{13}$ Both Hollingsworth, Wing, and Bradford (2019), and Maclean, Ghimire, and Nicholas (2020) report similarly large effect sizes in their analyses of RML effects in the NSDUH. Dragone et al. (2019) study the legalization of recreational marijuana in Washington and Oregon (compared to border counties) also using NSDUH data, and find that RML adoption increases marijuana use by roughly $25 \%$. Maclean, Ghimire, and Nicholas (2020) use administrative data on admissions to substance use disorder (SUD) treatment and show that marijuana-related SUD treatment admissions among all adults 21 years and older increase by

\footnotetext{
${ }^{11}$ In some states, the WC program reimburses injured or ill employees for medical marijuana. However, to the best of our knowledge, that is not the case for recreational marijuana.

12 There is also a large literature that attempts to estimate the impact of direct measures of individuals' marijuana use on labor market outcomes. See, for example, Zwerling, Ryan, and Orav (1990), Register and Williams (1992), Macdonald et al. (2010), and Williams and van Ours (2020).

${ }^{13}$ Studying adolescent marijuana use, Cerdá et al. (2017) investigate the effect of legalizing recreational marijuana in the state of Washington and find an increase of up to $4 \%$ for this age group.
} 
$26 \%$ or more post-law. This measure likely captures particularly problematic marijuana use which could negatively impact health and labor market outcomes. On net, most studies to date show a non-trivial increase in measures of marijuana use following RML adoption. ${ }^{14}$

A small literature considers whether RMLs appear to reduce use of pain management therapies, which are therapeutic substitutes for marijuana (Wen and Hockenberry 2018; Carrieri, Madio, and Principe 2020; McMichael, Van Horn, and Viscusi 2020). For example, Wen and Hockenberry (2018) document that, post-RML, prescriptions for chronic pain medications (therapeutic substitutes for marijuana) decline by $6 \%$ among Medicaid enrollees. Since all states adopting RMLs previously had MMLs, this finding suggests that RMLs impact access to marijuana for pain management purposes even beyond the extent to which MMLs do (Bradford and Bradford 2016, 2017). Similarly, Chan, Burkhardt, and Flyr (2020) show that RMLs reduce opioid mortality by $20 \%$ to $35 \%$, implying that both opioid use and misuse decline as legal marijuana access expands.

Marijuana access may influence labor market outcomes, although the direction of the relationship may vary across demographics and margins of labor market engagement. An important point of distinction is that the marginal user who is induced to consume marijuana following an MML versus an RML potentially differs. For example, RMLs permit legal access to marijuana (regardless of intent) for adults 21 years and older, while MMLs allow only individuals who can demonstrate a legitimate medical need for the medication for a specified set of conditions. Thus, the number of individuals who gain access to marijuana following an RML adoption is likely much larger than the number gaining access post-MML, which can be quite

\footnotetext{
${ }^{14}$ We note that Hansen, Miller, and Weber (2020) observe no change in marijuana-involved traffic fatalities following RML adoption in Oregon and Washington relative to comparison groups generated using synthetic control methods. These null findings suggest that marijuana legalization does not lead to increases in a particularly costly negative externality associated with substance use.
} 
restrictive in some states (Smart 2015), and the populations potentially have different underlying health statuses (i.e., the population gaining access to medical marijuana through an MML is likely sicker than that for RMLs). Based on our calculations, in 2019, 2\% of the population in MML states was eligible for medical marijuana. ${ }^{15}$ Alternatively, all older adults can legally access marijuana in states with RMLs. These features, and likely others, of the policies and their target populations potentially lead to different groups of new users and, in turn, heterogeneous implications for labor market outcomes.

A small literature studies changes in labor market outcomes due to MML adoption. Using the CPS, Sabia and Nguyen (2018) conclude that the passage of an MML permitting open marijuana dispensaries may decrease wages among younger males but has limited effect on other individuals. Nicholas and Maclean (2019) focus on adults 50 and older in the Health and Retirement Study and document that passage of an MML leads to an increase in the probability of working full-time and the number of hours worked per week among those participating in paid employment. Ullman (2017) finds that increased marijuana consumption due to MML adoption reduces work absences as measured in the CPS. Anderson, Rees, and Tekin (2018) show that workplace fatalities fall following MML passage among workers 25 to 44 years (coefficient estimates are imprecise for other age groups). Finally, in related work, Ghimire and Maclean (2020) find that following the adoption of an MML, WC benefit receipt declines by $7 \%$. The decline is driven primarily by older adults, for whom the probability of receiving WC benefits declines by $13 \%$ post-MML. This finding further motivates the choice of sample in this paper.

\footnotetext{
${ }^{15}$ Calculations made using data from: https://www.statista.com/statistics/743485/medical-marijuana-patientpopulation-united-states-by-state/ and https://www.mpp.org/issues/medical-marijuana/state-by-state-medicalmarijuana-laws/medical-marijuana-patient-numbers/ (last accessed January 27, 2021).
} 
Of particular relevance to our work, four recent studies examine the impact of recreational marijuana access on labor market and social insurance outcomes. First, Chakraborty, Doremus, and Stith (2020), using county-level data over the period 2011 to 2018 from Colorado, show that the opening of dispensaries (but not RMLs per se) reduces unemployment rates but has minimal effects on labor market participation or wages. Second, Maclean, Ghimire, and Nicholas (2020), using data from the Social Security Administration, show that disability applications for disability - Social Security Disability Insurance (SSDI) and Supplemental Security Income (SSI) - increase post-RML, but successful applications (i.e., applications awarded benefits by SSA reviewers) are not appreciably changed following law passage. They also find that RML adoption does not lead to observable changes in wages or labor force participation rates among adults (though the unemployment rate declines by $6 \%$ ). Third, Abouk and Adams (2019) show that employment propensity increases post-RML. ${ }^{16}$ Dong (2020), using administrative WC data from Oregon, shows that workplace injuries increase after a county legalizes the sale of recreational marijuana, with effects driven by younger workers.

All states that have adopted an RML to date, with the exception of Maine, allow employers to enforce a zero-tolerance workplace and to fire workers for off-work marijuana use. ${ }^{17}$ Thus, some workers who would otherwise use marijuana (medically or recreationally) following an RML adoption may be deterred from using this product for fear of job loss. We expect fear of job loss to mute the possible gains and harms of RMLs.

\subsection{Possible mechanisms for a relationship between legalized recreational marijuana and} Workers' Compensation benefit receipt

\footnotetext{
${ }^{16}$ The authors note some declines in employment among women with young children post-RML, however. ${ }^{17}$ Please see https://www.nolo.com/legal-encyclopedia/state-laws-on-off-duty-marijuana-use.html (last accessed January 27, 2021).
} 
We hypothesize that access to marijuana through RMLs increases its medical use and, in turn, allows better management of symptoms that impede work capacity - e.g., chronic pain, insomnia, mental health problems, nausea, and so forth (Watson, Benson, and Joy 2000; Lynch and Campbell 2011; Hill 2015; Whiting et al. 2015; National Academies of Sciences and Medicine 2017). Chronic pain management is likely to be particularly important in our context as this is the health condition most commonly reported among medical marijuana users (Park and Wu 2017; Kosiba, Maisto, and Ditre 2019; Reinarman et al. 2011). For example, in a recent meta-analysis by Kosiba, Maisto, and Ditre (2019), 64\% of patients reported using marijuana to treat chronic pain. Improvements in symptom management may prevent an individual from receiving WC or may shorten the period of job separation as has been documented in the context of MMLs (Ghimire and Maclean 2020).

There are other possible mechanisms that could also lead to changes in WC benefit receipt following an RML adoption. We next describe these channels and then, in Sections 4 and 5, empirically test them alongside tests about the role of changes in work capacity.

RML adoption could lead to changes in both labor supply- and demand-side factors which could plausibly impact WC benefit receipt. In terms of labor supply, marijuana obtained post-RML and used recreationally could reduce labor supply through addiction (Volkow et al. 2014); impaired mental and physical health (Van Ours and Williams 2012; Van Ours et al. 2013); reduced human capital accumulation (Chatterji 2006); worsened cognition, concentration, and mental functioning (Hanson et al. 2010; Volkow et al. 2014; Winward et al. 2014); and reduced motivation (Irons et al. 2014). Such pathways may prompt some workers, perhaps those marginally attached to the labor market or with preexisting conditions, to place a WC claim. 
In terms of labor demand, RMLs may offer a boost to the economy (Chakraborty, Doremus, and Stith 2020; Nicholas and Maclean 2019). Improved labor market opportunities (in terms of the number of jobs) could increase WC receipt as there are more employed individuals 'at risk' for a work-related injury. Labor demand shifts could also affect the composition of employed individuals, leading to ambiguous effects on the propensity to claim/duration of WC benefits. As the number of available jobs is rising with increased demand for recreational marijuana, employees may be less concerned about possibly sending a negative signal regarding their productivity to the employer (and thereby risking job loss as a result) through placing a WC claim, thus benefit receipt could increase post-RML. Alternatively, economy-wide demand shocks may lead to employers prioritizing workplace safety and training (Charles et al. 2019), thus minimizing risk of a work-related injury and WC receipt.

Moreover, additional marijuana use could increase workplace injury rates, especially traumatic injuries, by worsening concentration. Kaestner and Grossman (1998), for example, provide some evidence that drug use increases workplace injuries among males. On the other hand, as noted in Section 2.2, Anderson, Rees, and Tekin (2018) show a decline in fatal workplace injuries post-MML among some worker groups. Thus, the net effect on injury rates is an empirical question, and we will consider a range of possible mechanisms.

\section{Data and methods}

\subsection{Data}

\subsubsection{Workers' Compensation data}


Our primary dataset is the 2011 to 2019 ASEC, prepared by the Integrated Public Use Microdata (IPUMS) system (Flood et al. 2020). ${ }^{18,19}$ The ASEC is fielded each year between February and April, and collects detailed information on income, insurance, poverty, and other socio-economic variables on approximately 150,000 respondents. ${ }^{20} \mathrm{WC}$ income in the ASEC reflects income received over the previous calendar year, thus our analysis captures WC income received over the period 2010 to 2018. When discussing these data, we will refer to the calendar year (which we label 'year'), not the survey year.

ASEC information is self-reported; however, given that state WC systems are independent, locating harmonized national sources with detailed information about recipients, such as age, is difficult. The ASEC is commonly used by economists to study WC outcomes at a national level (Ghimire and Maclean 2020; Krueger 1990; Gruber and Krueger 1991; Hirsch, Macpherson, and DuMond 1997; Bronchetti and McInerney 2012; Bronchetti and McInerney 2019). For this reason, we view the ASEC as the most suitable dataset for our research.

We truncate the sample at 62 as most Americans become eligible for Social Security benefits at this age and access to this income support may impact decisions to claim WC that we cannot accurately model. Results are similar if we include adults up to age 65 years. We exclude respondents with remaining missing information on $\mathrm{WC}$ and demographics (outlined in Section 3.5). We have 517,351 respondents in our analysis sample.

3.1.2 Marijuana use and misuse, and prescription medication use

\footnotetext{
${ }^{18}$ We exclude the survey collected in 2020 (which captures claiming in 2019) due to the COVID-19 pandemic. We are concerned that this unprecedented public health crisis may have impacted reporting.

${ }^{19}$ The American Community Survey (ACS) does not collect information specifically on WC benefit receipt. We cannot isolate income from WC from other sources, thus the ACS is not suitable for our research question.

${ }^{20}$ There was a change in the ordering of some of the income questions in 2014 in the ASEC (Hill et al. 2019). We do not suspect that this change impacts our analysis since we include year fixed effects in all regression models, accounting for such national changes.
} 
To provide evidence on the 'first-stage' effect, we examine the impact of RMLs on measures of marijuana use and misuse. To study use, we utilize the public state-level biennial NSDUH files (2010-2018). ${ }^{21}$ A limitation of these data is that we cannot isolate adults 40 to 62 , instead we examine past month and past year marijuana use among adults 26 years and older. ${ }^{22}$

To study a measure of misuse, we draw data on marijuana-related admissions to SUD treatment, selecting on ages 40 to 64 years of age from the Treatment Episode Dataset (TEDS). ${ }^{23}$ TEDS is a national database of approximately two million SUD treatment admissions per year that is used by the federal government to track SUD treatment (Substance Abuse and Mental Health Services Administration 2018). We use TEDS data on admissions for which the primary substance associated with treatment is marijuana and any marijuana is reported at admission over the period 2010 to $2018 .^{24} \mathrm{We}$ aggregate the TEDS data to the state-year level. We have 450 state-year observations in the TEDS data, these data exclude some states in some years and we are left with 450 observations from 51 states.

We expect that post-RML workers may use marijuana rather than therapeutic substitutes. To test this hypothesis, we use data from the Medicaid State Drug Utilization Database (SDUD). The SDUD, managed by the Centers for Medicare and Medicaid Services, includes all prescription fills that are reimbursed by Medicaid. We use quarterly data from 2011-2018 and extract a set of medications used to treat chronic pain among Medicaid enrollees. ${ }^{25}$ We focus on

\footnotetext{
${ }^{21}$ We match RMLs (and all other covariates) to the NSDUH data on the second year in two year averages. For example, 2010 in the 2009/2010 file and 2011 in the 2010/2011 file. We then lag the RML variable by one year as outlined later in the manuscript.

${ }^{22}$ This is the most accurate stratification (for our older adult age group) that we can apply in the public use data. ${ }^{23}$ Age information is provided in bins in the TEDS and thus we cannot exclude those 63 to 64 years of age. TEDS does not include information on admission date below the year.

${ }^{24}$ Dave and Mukerjee (2011) estimate that TEDS covers two-thirds of SUD treatment received in stand-alone facilities in the U.S. TEDS records up to three substances at admission.

${ }^{25}$ We use a set of medications that are commonly used by Medicaid enrollees to treat pain prepared by Ashley Bradford and Shyam Raman. This list includes opioids such as OxyContin and non-narcotic analgesics such as Tylenol. The full list of medications is available on request. Beginning in 1992 all state Medicaid programs have
} 
pain as this is the most common condition reported by medical marijuana users. A limitation of using the SDUD for our purposes is that these data only capture prescriptions from one payer.

\subsubsection{Workplace injury rates}

As a complementary measure to our WC outcomes, we use administrative Bureau of Labor Statistics (BLS) data on the number of non-fatal workplace injuries among those 40 to 62 years of age in each state over the period 2011 to $2018 .{ }^{26}$ The BLS Survey of Occupational Injuries and Illnesses (SOII) collects workplace injury data from approximately 200,000 employers. ${ }^{27}$ We use nonfatal cases involving days away from work as our measure of workplace injuries. This SOII variable shares some useful characteristics with WC benefit receipt since both require time away from work due to workplace injuries. The SOII measure does not necessarily imply WC benefit receipt ${ }^{28}$ offering an opportunity to distinguish between changes in injury rates and WC outcomes conditional on injury. The SOII data exclude some states and we are left with 337 observations from 41 states.

\subsubsection{Broader labor supply measures}

To understand the broader context of changes in WC benefit receipt following RML adoption, we also study labor supply more generally. The ASEC provides past calendar year measures of labor force participation and usual hours worked per week. In addition, we use the

\footnotetext{
been required to report fee-for-service prescription fills to CMS in return for the ability to participate in the federal government Medicaid Prescription Drug Rebate program. Prior to March 23, 2010 states were not required to report managed care Medicaid prescription fills. We follow several studies in the literature and use data from 2011 onward (although results, available on request, are not appreciably different if we include 2010 in the sample) and we exclude quarters that display substantial variation in reporting, which we define as a quarter-over-quarter change that falls at or below the $10^{\text {th }}$ percentile of the empirical distribution or at or above the $90^{\text {th }}$ percentile of the empirical distribution, a full listing of excluded observations is available on request. We also exclude DC and Rhode Island as CMS has documented irregularities in reporting on the part of these localities. See the supplementary material reported in Wen and Hockenberry (2018) for a full discussion of this issue.

${ }^{26}$ There are concerns about the quality of the data prior to 2011 so we begin our analysis with the 2011 data.

${ }^{27}$ Some groups are excluded from this dataset such as federal employees, the self-employed, and workers on farms with ten or fewer workers.

${ }^{28}$ Workers are often ineligible for cash WC benefits unless they miss at least three days of work.
} 
basic monthly CPS data to study weekly employment, whether the respondent has a worklimiting disability, and whether the respondent was absent from work for a health-related reason in the past week. The basic monthly CPS collects information on employment, labor supply, and demographics on 150,000 respondents from approximately 50,000 households. We use the 2010 to 2018 monthly surveys since the information collected is point-in-time and thus this time period matches our ASEC years.

\subsubsection{Number of establishments}

We also use data from the U.S. County Business Patterns (CBP) dataset 2010 to 2018 to study if there are changes in the number of establishments post-RML. We consider the total number of establishments and those that are arguably most likely to be impacted by an expanding recreational marijuana market using results from Chakraborty, Doremus, and Stith (2020). ${ }^{29}$ We aggregate the CBP data to the state-year level and observe all states in all years.

\subsection{RML Coding}

Data on RMLs are obtained from Chan, Burkhardt, and Flyr (2020), and ProCon.org (2020b). ${ }^{30}$ We match the RML variable to our data based on state, month, and year. ${ }^{31}$ In our main regression model, we lag this variable by one year to allow for marijuana legal status to change, older adults use the product, symptoms change, and WC benefit receive changes. In robustness tests, we explore the importance of recreational marijuana dispensaries, outlets in which consumers can legally purchase marijuana. Figure 2 graphically depicts states that have

\footnotetext{
${ }^{29}$ The CBP data pertain to the week of March 12 of each year. These data are based on tax returns collected by the Internal Revenue Service. The U.S. Census defines an establishment as '... a single physical location at which business is conducted or services or industrial operations are performed.'

${ }^{30}$ We have also confirmed our effective dates using internal RAND policy data, PDAPS, NORML.org, and our own reading of original state statutes where inconsistencies across sources appear. Full details on request.

${ }^{31}$ The aggregate data we study do not have month information, thus we match on the first year in which a law is in place for at least six months. Put differently, if an RML is adopted between January and June in year $t$, we code the law as in place in year $t$ and all following years. On the other hand, if an RML is adopted between July and December of year $t$, we code this RML as zero in year $t$ and one in year $t+1$ and following years.
} 
adopted or announced an RML by December 2020. By the end of our study period (2018), nine states and DC had an RML in place, although 15 states and DC had adopted or announced such a law by December 2020.

\subsection{State-level control variables}

We control for several state-level variables that are potentially correlated with RML adoption and WC benefit receipt in our regression models (outlined in Section 3.5). In particular, we control for medical marijuana laws (Sabia and Nguyen 2018; ProCon.org 2020b), prescription drug monitoring programs or PDMPs (Ali et al. 2017), naloxone \& Good Samaritan laws (Prescription Drug Abuse Policy System 2020), ${ }^{32}$ and pain clinic management laws (Prescription Drug Abuse Policy System 2020). In addition, we control for several state-level labor market policies and characteristics: the effective minimum wage (in 2018 dollars), the state earned income tax credit (EITC) as a share of the federal EITC, political party of the state governor, ${ }^{33}$ and population (University of Kentucky Center for Poverty Research 2020). ${ }^{34}$

\subsection{Primary WC outcomes and summary statistics}

We consider two measures of WC benefit receipt based on survey responses in the ASEC. First, we use an indicator for any WC income. Second, we examine the level of WC

\footnotetext{
${ }^{32}$ We code these two variables as one indicator that takes on a value of one if a state has both policies in place following Ghimire and Maclean (2020). The logic for this coding structure is that the two laws work more effectively together. Naloxone laws provide access to this medication while Good Samaritan laws provide legal protection for the administrator of the medication. Our results are not meaningfully affected if we instead code these policies as two separate variables, indeed coefficient estimates are nearly identical and are available on request.

${ }^{33}$ We treat the mayor of DC as the governor of that locality following Maclean and Saloner (2018).

${ }^{34}$ In unreported analysis, we control for the state unemployment rate to account for changes in economic conditions, which may impact the decision to claim WC. Results are not appreciably different. However, the unemployment rate is potentially impacted by RML adoption, thus we do not report this specification as we are concerned about inducing over-controlling bias (Angrist and Pischke 2008). In our analysis of the SDUD, we include an indicator for Medicaid expansion with the Affordable Care Act obtained from the Kasiser Family Foundation (2021). These Medicaid expansions lead to a substantial increase in the number of enrollees and also a change in the composition of enrollees as the 'newly eligible' are largely non-disabled childless adults. Thus, controlling for this policy change is important in the SDUD. In unreported analyses, we have re-estimated our main WC regressions including the ACA Medicaid expansion variable and results are nearly identical. Results are available on request.
} 
income (in 2018 dollars). These outcomes refer to receipt of cash benefits only and we will frequently refer to them as 'WC benefits,' though they exclude medical benefits, ${ }^{35}$ vocational rehabilitation vouchers, and other types of reimbursements provided by WC systems.

Table 1 reports summary statistics for the full sample of states and then stratified by RML adoption. Data are weighted by ASEC-CPS provided survey weights. For adopting states, the summary statistics refer to the average prior to adoption. Just under $1 \%$ of the full sample reports receiving WC benefits and the average WC income in the sample is $\$ 75$ overall. $6.2 \%$ of the sample resides in a state with an active RML during our time period, reflecting that most RMLs were adopted closer to the end of the sample. State- and individual-level characteristics are broadly similar across the two groups of states. We discuss balance further in Section 4.3.2.

Appendix Figure 1 reports trends in any WC income and WC income (in 2018 dollars) over our study period. Both outcomes are trending downward modestly, which is in line with trends in costs based on administrative data (Figure 1A).

\subsection{Methods}

We estimate two-way fixed effects (TWFE) models to study the impact of RML passage on WC benefit receipt outcomes:

$$
W C_{i, s, t}=F\left(\beta_{0}+\beta_{1} R M L_{s, t-1}+P_{s, t} \beta_{2}+X_{i, s, t} \beta_{3}+\theta_{s}+\tau_{t}+\varepsilon_{i, s, t}\right),
$$

where $W C_{i, s, t}$ is a WC outcome for respondent $i$ in state $s$ in calendar year $t . R M L_{s, t-1}$ is an indicator variable for an RML in state $s$ in year $t-1$. We lag the RML variable one year to permit time for the policy to have an impact, though we show in robustness checks that our results are not sensitive to this decision. $P_{s, t}$ is a vector of state-level time-varying factors including policies that target marijuana or related substances that can be used to manage chronic pain. We

\footnotetext{
${ }^{35}$ Many WC claims are 'medical only' and do not involve any lost work time (Weiss, Murphy, and Boden 2020).
} 
provide evidence about the importance of these control variables in Section 4.3. $X_{i, s, t}$ is a vector of respondent-level characteristics (i.e., age, sex, race, ethnicity, and education). ${ }^{36}$

We include state $\left(\theta_{s}\right)$ and year fixed effects $\left(\tau_{t}\right)$, the former account for time-invariant state factors while the latter control for shocks that impact the nation as a whole. When the outcome is binary, we assume $F(\cdot)=\Phi(\cdot)$ and estimate a probit model, reporting average marginal effects. ${ }^{37}$ For the level of WC income, we estimate using least squares; i.e., $F(\cdot)=$ $1(\cdot)$. We apply ASEC survey weights provided by IPUMS in our analyses of WC benefit receipt outcomes, although as we show in robustness analyses unweighted results are similar. We cluster standard errors by the state (Bertrand, Duflo, and Mullainathan 2004) in our main analysis. We will also conduct inference using a score bootstrap and permutation tests, given that these approaches can often have better properties for a small number of treated clusters.

When we examine other measures of work capacity in the monthly CPS, we use a probit model (reporting average marginal effects) for binary outcomes (e.g., any SSDI income) and linear models for continuous outcomes (e.g., hours worked), comparable to our ASEC analyses. We weight the data by the basic monthly person weight when the outcome is derived from the basic monthly CPS (e.g., work-limiting disability) and the ASEC weight for ASEC variables.

Many of our other outcomes are available at the state-year level. In analyses of aggregate data (i.e., NSDUH, TEDS, SOII, and CBP), the outcomes are rates per 100,000, except for SDUD outcomes in which case we report per Medicaid older adult enrollee. We estimate these models using weighted least squares. We include the same controls in these models although we replace the individual controls with state-level annual averages from the monthly CPS.

\footnotetext{
${ }^{36} \mathrm{We}$ include age in years, sex (male and female, male is omitted), race (white, African American, and other, white is omitted), ethnicity (Hispanic and non-Hispanic, non-Hispanic is omitted), and education (less than high school, high school, some college, and a college degree or higher, less than high school is omitted).

${ }^{37}$ We estimate the implied change in probability for each treated observation and then report the average change.
} 
This research design leverages within-state variation over time. The identifying assumption is that, after conditioning on included covariates, the error term in Equation (1) is uncorrelated with $R M L_{s, t-1}$. In Section 4.3, we explore the empirical importance of several common threats to identification: violation of parallel trends, unobserved heterogeneity, violation of the conditional independence assumption, and program-induced migration. Broadly, our analysis suggests that these threats to identification do not drive our findings.

Finally, we report 'counterfactual outcomes' in our tables to help benchmark the magnitudes of the coefficient estimates. These counterfactual outcomes are estimated using a baseline regression model that controls for the RML and state and time fixed effects. ${ }^{38}$ We then subtract off the causal impact of RMLs to estimate the outcome value in the absence of RML adoption. We report the average of these 'untreated' outcomes for all treated observations.

\section{Results}

We first present evidence about the impact of RMLs on marijuana use, misuse and pain medication drug prescriptions. Next, we evaluate the impact of RML adoption on WC outcomes and consider a number of explanations for this reduced form relationship. Finally, in the next section, we consider different pathways through which RMLs may affect WC benefit receipt.

\subsection{Marijuana use and misuse, and prescription medication use}

The literature provides ample evidence that RMLs increase adult marijuana use on the order of 20-38\% (Cerdá et al. 2020; Dragone et al. 2019; Hollingsworth, Wing, and Bradford 2019; Maclean, Ghimire, and Nicholas 2020). We replicate this analysis using the public use National Survey on Drug Use and Health (NSDUH). A limitation of the public use NSDUH is

\footnotetext{
${ }^{38}$ Alternatively, we could present the counterfactual outcomes implied by each model (i.e., including covariates). As we will show, the RML estimates are relatively stable across models so, for the sake of consistency, we hold the calculation of the counterfactual outcomes constant.
} 
that we cannot isolate older adults and instead examine marijuana use among all adults 26 years and older (Table 2A). We document large increases in marijuana use post-RML: a $1.85 \mathrm{ppt}$ (17.9\% compared to the counterfactual) increase in any past month and a $2.39 \mathrm{ppt}(15.6 \%$ compared to the counterfactual) increase in past year marijuana use. ${ }^{39}$

Marijuana use may also induce harms. To explore this possibility for our age group, we assess whether RMLs lead to increased problematic use of marijuana among older adults using data on marijuana-related admissions to SUD treatment in the TEDS. Results are reported in Table 2B. We find no evidence that this measure of problematic marijuana use increases postRML. In fact, the coefficient estimates are negative (though statistically insignificant). We also do not observe changes in admissions to treatment that are not related to marijuana: we construct a measure that includes admissions that do not list marijuana on the admission record. We again estimate negative and statistically insignificant effects.

This increase in marijuana use coincides with meaningful reductions in use of opioids following RML adoption (Carrieri, Madio, and Principe 2020; Wen and Hockenberry 2018; McMichael, Van Horn, and Viscusi 2020). Additionally, the literature finds that RMLs reduce opioid-related mortality (Chan, Burkhardt, and Flyr (2020) which is, again, in line with using marijuana for pain management purposes in cases in which alternatives may be more dangerous. Thus, there is substantial scope for RMLs to impact pain management as well as other outcomes related to a large expansion of recreational marijuana use and sales. To test for substitution from prescription medications used to treat chronic pain and marijuana in our time period and specification, we estimate the impact of RML adoption on prescription fills in the SDUD (Table

\footnotetext{
${ }^{39}$ The differences compared to the literature are due to conditioning on different sets of covariates and our approach to calculating proportional effects.
} 
2B). Post-RML, the number of prescriptions decreases by 0.31 per older adult Medicaid enrollee or $7.2 \%$ compared to the counterfactual mean, suggesting substitution across pain therapies.

This section provides evidence, supporting findings in the literature, that marijuana use among adults increases substantially following RML adoption. This additional use is not accompanied with increases in marijuana-related dependence, though we also do not observe the full spectrum of marijuana-related harms so we cannot rule out possible harmful health consequences. Further, we show, similar to previous studies, that patients substitute marijuana for prescription medications used to treat chronic pain. Given this background, we now turn to our primary analyses of WC benefit receipt.

\subsection{Effect of RML passage on WC benefits}

Our main findings are reported in Table 3. We study how RML adoption impacts WC benefits. In the first column, we include state and year fixed effects but no time-varying controls. We estimate that RML adoption reduces the probability of WC benefit receipt by 0.14 ppts, statistically significant from zero at the $1 \%$ level. This effect implies a $15.6 \%$ reduction relative to the counterfactual benefit receipt rate ( 0.9 ppts). In Column 2, we add individuallevel demographic controls and the estimated effect is not meaningfully changed. We add statelevel controls in Column 3 and, again, the coefficient estimate is unaffected by these controls. Appendix Table 1 provides a full set of coefficient estimates from this specification. Finally, in Column 4, we repeat the Column 3 analysis except we do not population-weight the data. The coefficient estimate is very similar.

Our preferred coefficient estimate is the Column 3 estimate which finds that RML adoption leads to a reduction in WC receipt among adults 40 to 62 years of age by 0.18 ppts, equivalent to $20 \%$ reduction. The coefficient estimate is similar in magnitude as estimated in 
Ghimire and Maclean (2020) among older adults: 0.20 ppts (see Table 5 of that paper). This effect size is large, which is in line with the substantial effects on marijuana use found in the literature (see Section 4.1). While the relative effect size is large, we attribute that to the low baseline benefit receipt rate and we note that the lower tail of the $95 \%$ confidence interval shows that we cannot rule out a $4.7 \%$ decrease in the probability of receiving any income from WC.

In Panel B of Table 3, we estimate the effect of RML adoption on annual WC income, a measure which combines both the extensive margin effect (WC benefit receipt) as well as any intensive margin effects (e.g., shorter injury durations and thus claiming periods). ${ }^{40}$ This result is robust to including individual controls (Columns 2), state policy controls (Column 3), and removing population weights (Column 4). In our preferred model - Column 3 - we estimate that RMLs decrease WC income by $\$ 21.98$ or $20.5 \%$ (compared to the counterfactual mean).

The WC results suggest that the large change in marijuana use established in other work and our own analyses may be at least partially due to increased use for pain management, leading to a reduction in $\mathrm{WC}$ receipt. We explore mechanisms in Section 5.

Due to concerns about inference in TWFE models with only a few treated units (Brewer, Crossley, and Joyce 2017), we also include $t$-statistics generated by testing the null hypothesis of no effect using a score bootstrap approach (Kline and Santos 2012) for our preferred specification (Column 3) ${ }^{41}$ For both WC outcomes, we can reject the null hypothesis at the 5\% level. We will present permutation tests as well (see Section 4.3.4).

\subsection{Internal validity}

\subsubsection{Parallel trends}

\footnotetext{
${ }^{40}$ We note that we cannot fully separate duration of the claim from higher wages and thus higher benefits. However, we do control for education and other demographics which are correlated with wages.

${ }^{41}$ We implement this approach using -boottest- in Stata (Roodman et al. 2019).
} 
To test for possible threats to identification, we first estimate an event study to assess whether RML adopting and non-adopting states have different pre-existing trends. We include time-relative-to-adoption indicators from four years pre-policy through one year (or more) postpolicy, normalizing any differences between adopting and non-adopting states five or more years (the omitted category) before adoption to zero. The zero category represents the year of RML adoption. We group all other post-adoption years into one or more years post-policy as we have few post-years. ${ }^{42}$ Several states adopted an RML after 2018, we observe these states in their pretreatment period and account for this change. ${ }^{43}$ States that did not adopt an RML or announce a date for a future RML by December 2020 are coded as zero for all lead and lag variables.

Figure 3, Panel A examines the propensity of WC receipt by year-relative-to-RML adoption. There is little evidence of any systematic pre-adoption differences, relative to the omitted category, between adopting and non-adopting states. At the time of adoption, there is a notable relative decline in $\mathrm{WC}$ benefit receipt. This reduced incidence persists into the next periods. We observe a similar pattern of coefficient estimates in Panel B for annual WC income. Thus, Figure 3 suggests that the reduction in WC benefits in adopting states is not an artifact of systematic trends existing prior to RML adoption.

\subsubsection{Possible confounders}

Next, we examine characteristics that predict RML passage to understand what is changing in adopting states relative to non-adopting states. To this end, we aggregate the data to the state-year level and regress the RML variable on state-level policies and demographics, and

\footnotetext{
${ }^{42} \mathrm{We}$ do not apply a lag in construction of the event study indicators. As a specific example, the zero period in our event study is the year of RML adoption, not the year of adoption lagged one year.

${ }^{43}$ For example, states that adopt a policy in 2019 are observed one-year pre-RML in 2018 and two years pre-RML in 2017, we code these states as one for the one-year policy lag in 2018 and one for the two-year policy lag in 2017. If we do not account for the fact that we observe these states in their pre-treatment period, we would incorrectly classify them in the comparison group which could lead to inaccurate conclusions regarding the ability of our data to satisfy the parallel trends assumption (Schmidheiny and Siegloch 2020).
} 
state and year fixed effects. Results are listed in Appendix Table 2. We find that states adopting naloxone \& Good Samaritan laws and higher minimum wages are more likely to adopt an RML, while states with increasing shares of African Americans and Hispanics are less likely to do so. After conditioning on covariates, MML adoption and most of the laws in the model designed to curb access to opioids through supply-side efforts (e.g., PDMPs) do not predict RML adoption.

Additionally, we follow the logic of Altonji, Elder, and Taber (2005) and explore the sensitivity of our results to different sets of control variables. If our coefficient estimates change substantially as we include different sets of control variables, then we may be concerned that our findings are driven by unobservable heterogeneity rather than capturing true RML effects. We start from a regression specification that includes only the RML indicator, and state and year fixed effects (the same as Table 4, Column 1). To this parsimonious model, we sequentially include each state- and individual-level control variable and observe how the coefficient estimates change. Results are reported in Appendix Table 3. Our coefficient estimates are not appreciably changed as we add covariates. For any WC receipt, the coefficient estimates range from -0.0018 to -0.0015 , compared to our baseline coefficient estimate of -0.0018 . Thus, we conclude that the results are largely insensitive to the inclusion of any specific control.

\subsubsection{Migration}

Next, we explore the extent to which RML adoption leads to changes in migration patterns: are individuals more likely to move into or out of the state after RML adoption? Such behavior, if present, is a form of program-induced migration (Moffitt 1992) or a violation of the stable units assumption required for TWFE methods, and can lead to bias in regression coefficient estimates. To explore this possibility, we use information on past-year migration available in the ASEC. We construct measures of any migration, moving to an RML state from 
a non-RML state (in-migration), and moving from an RML state to a non-RML state (outmigration). Results are reported in Appendix Table 4 and do not reveal any evidence that RMLs induce migration among our age group. Previous work, based on the full sample of adults, provides more evidence of migration effects (Maclean, Ghimire, and Nicholas 2020; Carlin et al. 2020), which may suggest that younger adults or perhaps even adults ages 63 and above (who are not in our sample) migrate following adoption of an RML.

\subsubsection{Falsification exercise}

In this section, we conduct a falsification exercise. We randomly re-shuffle our RML variable across states and years 100 times, and re-estimate Equation (1). In our randomization process, we hold constant the number of states that adopt within each year. We follow MacKinnon and Webb (2020), and report $t$-statistics from this exercise. Results of the placebo analysis are reported in Figure 4. We mark the 2.5 and 97.5 percentiles of the placebo distribution as well as the $t$-statistic generated when RMLs are correctly assigned. We find that our main results are unlikely to occur by chance as the main $t$-statistics are below the $2.5^{\text {th }}$ percentile of the placebo distributions.

\subsubsection{Additional sensitivity tests}

Finally, we report the results of a series of sensitivity tests in Appendix Table 5A. We find that our point estimates are robust to including state-specific linear time trends (Panel A) and Census region-by-year fixed effects (Panel B). The coefficient estimates are also similar

if we limit the sample to state-year pairs for which we have data on SUD treatment admissions in the TEDS sample (Panel C) and injury rates from the SOII (Panel D). Additionally, we consider the consequences of our decision to lag the RML variable. In Panel E, we present results in which we use the contemporaneous RML. The results are similar. We also control for 
respondent industry fixed effects (Panel F) and occupation fixed effects (Panel G). ${ }^{44}$ While there may be concerns that RMLs impact labor supply decisions on these margins, we find that the coefficient estimates are unaffected by the inclusion of these fixed effects. Next, in Panel H, we aggregate the data to the state-year level. ${ }^{45}$ The coefficient estimates and standard errors are similar. In Panel I, we add controls for state-level WC policy variables (i.e., maximum weekly benefits). Our results do not appear to be driven by concurrent shifts in WC benefit generosity. Finally, in Panel J we apply a method proposed by de Chaisemartin and d'Haultfoeuille (2020a, 2020b) that accounts for heterogeneity in treatment effects. Our results are robust. ${ }^{46}$

In Appendix Table 5B, we report results based on different regression model specifications. We use a linear probability model for WC benefit receipt. For the WC income variable, we use a Poisson model (Column 2, average marginal effects are reported). Our main coefficient estimates do not appear to be driven by our choice of functional form.

We also conduct a 'leave-one-out' analysis to assess differences across states in RML effects. While we use a single indicator for law passage, each law has unique characteristics (ProCon.org 2020b) and therefore a potentially different effect on WC benefit receipt. We sequentially drop each treatment state from the sample and re-estimate Equation (1). This exercise allows to explore whether our main findings (Table 3) are driven by the experience of a specific state(s). We report the leave-one-out analysis results graphically in Appendix Figure 2;

\footnotetext{
${ }^{44}$ For both industry and occupation fixed effects we include a separate fixed effect for those not in the labor market.

${ }^{45}$ In this analysis, we aggregate the individual level data to the state-year level. More specifically, we take the average values of each individual-level variable.

${ }^{46}$ We provide average effects using a weighted (by the number of 'switchers') average of five post-period effects minus the weighted average of three pre-period placebos using the -did_multiplegt- package in Stata. The postperiods are defined to only include fully-treated periods to exclude any partially-treated year, which is in line with lagging the RML variable in our main specification. To make the coefficient estimates more comparable to our main TWFE estimates, we use three pre-periods as the baseline instead of only the period prior to adoption. We cluster (by state) bootstrap this average effect estimate 500 times to estimate standard errors.
} 
any WC is reported in Panel A and WC income is reported in Panel B. Our findings are similar across the leave-one-out samples, suggesting effects are relatively homogenous across states. 4.3.6 Discussion of internal validity and sensitivity checking

In summary, we have probed the validity of our design to assess the empirical importance of several common threats to identification: (i) a violation of parallel trends, (ii) a violation of the CIA, (iii) unobserved heterogeneity, and (iv) program-induced migration. We also explore the robustness of our findings to alternative samples and specifications, and allow for heterogeneity across states in treatment effects. Our assessment of this testing is that our key results are not driven by violations of key model assumptions, other concurrent policies adopted by states, or the selected sample or specification.

\section{Mechanisms}

We find that RMLs reduce WC benefit receipt. RMLs may broadly impact the economy and, consequently, labor supply outcomes (including WC benefit receipt). RMLs may also impact pain management and work capacity. Our welfare calculus of RMLs and related policies depends on our understanding about how RMLs reduce WC benefit receipt.

To evaluate these different possible mechanisms, we study broader measures of labor supply as well as metrics of labor demand. We also study alternative measures of work capacity to provide complementary evidence of the scope for RMLs to impact that dimension of labor market participation.

\subsection{Changes in labor supply and labor demand}

We consider the possibility that overall labor supply is changing in response to RML adoption and present these results in Table 4A. We first evaluate the following outcomes available in the CPS: working in the past year, current labor force participation, working in the 
past week, and usual hours worked per week in the past year (unconditional and conditional on any hours worked). The results are presented in Table 4A.

We observe that, after RML adoption, the propensity to work in the past year increases by 0.54 ppts $(0.70 \%$ relative to the counterfactual $)$ while the number of hours usually worked per week increases by 0.28 hours or $0.70 \%$ (conditional on any hours). Both coefficient estimates are statistically significant from zero at the $10 \%$ level. Using the monthly CPS, we do not observe statistically significant changes in the probability of labor force participation or working in the past week or the unconditional number of hours worked, though all three coefficient estimates again suggest a positive relationship. The results in Table 4A cast doubt on the possibility that RMLs reduce WC benefit receipt mechanically through decreased labor supply (i.e., reduced opportunities to incur injuries at work). Instead, we observe evidence of increases in overall labor supply, which - all else equal - would predict that WC benefit receipt should increase post-RML as working exposes individuals to workplace injuries.

As a related measure, we study whether RML adoption leads to changes in the number of establishments using the 2010 to 2018 CBP data. We consider two measures of establishments: total number of establishment and number of establishment in industries plausibly related to the recreational marijuana market as examined by Chakraborty, Doremus, and Stith (2020). ${ }^{47} \mathrm{We}$ present these results in Table 4B. ${ }^{48}$ We observe an increase in both types of establishments postRML, although the coefficient estimates are not precise. These findings suggest, if anything, an increase in labor demand post-policy. Such changes should, all else equal, lead to increased WC

\footnotetext{
${ }^{47}$ We use the following NAICS codes: Natural Resources and Mining (11), Construction (23), Manufacturing (3133), Trade (42, 44-45), Information (51), Financial Activities (52), Education (61), and Health Services (62).

${ }^{48}$ For this analysis, we scale the outcome and weight the regression by the full population size.
} 
benefit receipt as workers are more exposed to workplace injuries. We consider the possibility of changes in the composition of jobs in Sections 5.2 and 5.3 below.

\subsection{Changes in workplace injury rates}

We next provide evidence about whether we are observing differences in WC receipt (possibly through differences in claiming behavior) versus differences in injury rates. We use workplace injuries reported in the SOII data, scaled by the population size for ages 40-62. ${ }^{49}$ These results are presented in Table 5. We estimate that RMLs reduce the workplace injury rate by 32 per 100,000 older adults, equivalent to about a $5.4 \%$ reduction relative to the counterfactual mean for the treated states.

The SOII data also permit us to evaluate injuries based on injury type. We separate traumatic injuries from non-traumatic injuries, and present the results in Columns 2 and 3 in Table 5. Injuries such as sprains, strains, tears, hernias, and burns are classified as traumatic injuries, including complex region pain syndrome. Non-traumatic injuries include low back disorders, infectious diseases, and cancer. While both categories potentially include injuries which benefit from pain management therapies (e.g., a traumatic injury may result in a sprain which requires pain management for the worker to continue working), our hypothesis is that the rate of non-traumatic injuries - which include longer-term chronic pain injuries - should be disproportionately impacted by RML adoption if this policy improves pain management therapy access. We observe reductions of 25 traumatic injuries and seven non-traumatic per 100,000 older adults, representing $4.5 \%$ and $23.4 \%$ reductions. Despite the imperfect categorization of injuries more 'exposed' to marijuana access for pain management purposes, we observe

\footnotetext{
${ }^{49}$ While the SOII data do not cover all state-years, we show in Appendix Table 5A, Panel D that the main WC results hold for the SOII sub-sample.
} 
especially large proportional effect sizes on the type of injuries we would likely expect to be more impacted by improved access to pain management therapy ex ante.

\subsection{Changes in industry composition}

We consider the possible role of changes to industry composition on affecting injury rates using the SOII data again. One possibility is that RMLs alter the local economy in a way that shifts workers to safer jobs, explaining the reduction in injury rates and WC benefit receipt. We test this possibility by assigning each worker in the ASEC with the injury rate ${ }^{50}$ of their industry in their state in 2011 (the year prior to the first RML adoption). ${ }^{51}$ The motivation behind this test is to hold constant the industry injury rate such that the outcome (conditionally) only varies due to systematic movements in industry composition and extensive labor supply decisions. Holding the injury rate constant shuts down any endogenous within-industry changes to the injury rate due to RML adoption. We observe no evidence of a change in the predicted injury rate (Table 5 Column 4), suggesting that the decreases estimated in Columns 1 to 3 are not due to changes in labor force participation or industry composition. ${ }^{52}$

We estimate increases in labor supply but reductions in workplace injury rates. These reductions disproportionately impact non-traumatic injuries. Moreover, they do not reflect changes in industry composition. The evidence we have presented so far does not suggest that the changes in WC are due to shifts in overall or industry-specific labor supply/demand. This finding also does not suggest that RML adoption induces a large labor demand shock that induces firms to considerably improve workplace safety since we would not necessarily expect

\footnotetext{
${ }^{50}$ Here, the injury rate is defined as injuries per 100,000 workers in the industry. Non-workers are assigned a workplace injury rate of zero.

${ }^{51}$ The SOII provides injury rates by NAICS. We map the NAICS codes to the 1990 Census industry codes provided in the IPUMS CPS.

52 The estimate is noisy, but implies a roughly $2 \%$ reduction in the predicted injury rate. This effect size is small compared to the $6 \%$ decrease implied by the Column 1 coefficient estimate.
} 
such improvements to disproportionately target the types of injuries also directly impacted by marijuana access. ${ }^{53}$ In the next section, we further consider the possible role of improvements in pain management and work capacity.

\subsection{Alternative measures of work capacity}

To further probe whether our findings are driven by changes in work capacity, we study complementary measures (in the CPS) of health and disability: self-assessed health, whether the respondent reports having a work-limiting disability, and absence from work in the past week due to a health-related reason. These results are presented in Table 6 . In the first column, the outcome is whether the respondent reports good, very good, or excellent health. In the second and third columns, the outcomes are whether the respondent reports a work-limiting disability and is absent from work due to a health-related reason respectively. We observe only small and statistically insignificant changes in self-assessed health or the propensity of being absent from work for a health-related reason post-RML, but the probability of reporting a work-limiting disability declines following law adoption (statistically significant at the $1 \%$ level). In particular, the propensity to report a work-limiting disability declines by 0.68 ppts due to RML adoption, or $6.2 \%$ relative to the counterfactual proportion for the treated states. This decline is consistent with work capacity improvements driving the $\mathrm{WC}$ results.

The null finding for work absences is also potentially informative regarding work capacity improvements attributable to RMLs. In particular, RMLs appear to impact longer-term health rather than short-term work separations. This pattern of results is again in line with the

\footnotetext{
${ }^{53}$ We cannot rule out that labor demand shocks cause firms to improve workplace safety primarily for these types of conditions, but we also do not find much evidence of RMLs creating large increases in labor demand (e.g., Table 4B) which would induce such improvements.
} 
hypothesis that RMLs allow better symptom management of health conditions that would otherwise require a substantial amount of time away from work.

\subsection{Discussion of mechanisms}

The objective of our study is to examine changes in WC benefit receipt, a proxy for work capacity, due to RML adoption and understand the possible mechanisms for this relationship. There are many pathways through which RMLs could reduce WC benefit receipt. We conjecture that improvements in the management of chronic pain and other health condition symptoms play a key role in the observed findings. Many of the alternative pathways discussed above would operate through observable changes in labor supply or demand, or industry composition. We observe increases in labor supply and no evidence of meaningful shifts to jobs which would decrease workplace injury rates. Thus, the mechanism does not appear to be related to a mechanical reduction in workplace injury incidence due to fewer people working or working in safer jobs.

In fact, we estimate that RMLs reduce workplace injury rates overall, disproportionately among injuries which we would expect to be more impacted by additional access to chronic pain therapies - non-traumatic injuries. Moreover, we find complementary reductions in self-reported work-limiting disabilities. These results suggest that RMLs positively impact work capacity, driving down injury rates and WC claiming. The increases in broader measures of labor supply are also consistent with this mechanism. The improvements in work capacity may originate from the increased use of marijuana to manage pain or through reductions in other medications which have harmful effects on labor productivity.

\section{Heterogeneity in RML effects}

\subsection{The importance of dispensaries}


In our primary analysis, we use an indicator for any RML and do not distinguish between policies that protect dispensaries, legal establishments in which individuals can purchase marijuana, and those that do not. We next include a second indicator variable in Equation (1) that takes the value of one if a state RML provides the legal framework for dispensaries to operate (we do not alter our main RML indicator). We also separately consider whether there is a legal and operational recreational dispensary in the state. We report results based on the augmented specifications in Appendix Table 6; Panel A reports results for a law that allows dispensaries and Panel B reports results that use the first legal recreational marijuana dispensary in operation in a state. We do not observe any evidence that, conditional on RML, dispensaries (either measured as the legal framework allowing dispensaries or dispensaries in operation) lead to additional changes in WC claiming. We report tests of the combined effect (RML + dispensary) at the bottom, and they are similar to our prior coefficient estimates, although we note that we lose precision in the specification with an operating dispensary. Overall, we do not observe evidence suggesting that dispensaries are particularly important; this pattern of null findings is similar to the MML context (Ghimire and Maclean 2020) and for other forms of social insurance (Maclean, Ghimire, and Nicholas 2020). ${ }^{54}$

\subsection{Heterogeneity by respondent characteristics}

We consider heterogeneity in RML effects across individuals based on the type of job they hold. We follow Ghimire and Maclean (2020) and separately consider those employed in 'physically demanding jobs' and other jobs. ${ }^{55}$ The magnitudes are larger for physically demanding jobs, though the differences are small (see Appendix Table 7).

\footnotetext{
${ }^{54}$ Maclean et al find evidence that dispensaries may impact SSI applications, but not SSDI applications.

${ }^{55}$ We define the following past-year occupational codes as 'physically demanding jobs.' To do so, we follow Ghimire and Maclean (2020) and use a harmonized 1990 past-year occupational coding scheme available in the IPUMS data to classify jobs into those that are physically demanding and those that are not. In particular, we use
} 
We estimate separate regressions for men and women (Appendix Table 8). While results are similar across the samples - coefficient estimates are negative and non-trivial in size, effect sizes are larger in the sample of men than women. Further, we lose power in the female sample likely due to lower shares of women receiving WC benefits.

\subsection{Heterogeneity across social insurance programs}

We next examine the impact of RMLs on the receipt of other benefits: SSDI and SSI given that WC benefit receipt often predicts subsequent enrollment in SSDI or SSI (O'Leary et al. 2012). SSDI provides income and health insurance (Medicare) for disabled workers who are not able to return to work. Correspondingly, SSI offers income and health insurance (Medicaid) to disabled individuals with very limited work history and financial resources. Both programs provide income support for the disabled, with some individuals being eligible for both programs (concurrent recipients). Results are listed in Appendix Table 9; SSDI results are reported in Panel A and SSI results are reported in Panel B. We observe a decline in SSDI receipt (both any income from this program and the level of income). In particular, we observe a decline of 0.30 ppt (21.4\% relative to the counterfactual outcome) in the probability of receiving SSDI.

Maclean, Ghimire, and Nicholas (2020) find that SSDI and SSI applications (but not awards) increase post-RML but are unable to stratify by age. Combined, these results suggest important age heterogeneity in terms of SSDI/SSI claiming behavior due to RML adoption.

\section{Discussion and conclusion}

the following IPUMS-created occupation variable: occ90ly. The following occupation codes are coded as physically demanding: 473 to 905 . We code all other occupations as not physically demanding. An example of a physically demanding occupation is a miner. An example of a non-physically demanding occupation is a pharmacist. We note that not all individuals report occupational information and thus the sum of the stratified samples is smaller than the full sample size. 
Our study evaluates the effect of recent laws legalizing recreational marijuana on workers' compensation benefits among adults ages 40 to 62 in the U.S. The analysis reveals a decline in WC benefit receipt by 0.18 ppts, equivalent to a $20.0 \%$ decrease, and annual income received from WC declines by $\$ 21.98$ (or $20.5 \%$ ) post-RML. We provide evidence that our results are not attributable to common threats to identification in TWFE models: differential pretrends between adopting and non-adopting states, unobservable confounders, and programinduced migration. We conduct a detailed analysis of mechanisms to understand this relationship. First, we show that marijuana use - but not misuse - increases post-RML and reduces prescriptions for medications used to treat pain. Second, our mechanism analysis provides suggestive evidence that our results are not attributable to an overall reduction in labor supply or systematic shifting into safer industries. Instead, we observe large reductions in nontraumatic workplace injuries and work-limiting disabilities, in line with improvements in work capacity among older adults.

The magnitudes of our coefficient estimates are reasonably similar to those found in the literature relating access to pain management therapies and measures of work capacity, though direct comparisons are difficult due to the varying contexts. Garthwaite (2012) estimates 10\% labor supply reductions resulting from the removal of Cox-2 inhibitors. ${ }^{56}$ Similarly, Bütikofer and Skira (2018) find the work sickness absences are very responsive to the introduction (7-12\% decreases) and removal (12-16\% increases) of these drugs from the market. Disability benefit receipt is also impacted following removal of these medications from the market.

\footnotetext{
56 This reduction refers to the labor supply of a population disproportionately impacted by access to pain management therapies. Our estimates can also be viewed in a similar context since we focus on WC benefit receipt, a margin which would also be disproportionately impacted by pain management.
} 
The effect size of marijuana legalization on WC claiming and income appears to be more substantial than that of MMLs on the same outcomes, as documented by Ghimire and Maclean (2020). In the present study, we find a $20.0 \%$ decline in WC claiming post-RML. In comparison, Ghimire and Maclean document a 13\% decline in WC claiming for older adults, after states adopted medical marijuana laws during the 1990 to 2012 period. The related magnitudes of the results are consistent with RMLs affecting a substantially larger share of the population (and all older adults that we study) than MMLs. These differential effects seem plausible as recreational marijuana is more readily accessible than medical marijuana for which the patient requires a formal prescription from a healthcare professional. The ability to purchase the medication 'over-the-counter' (OTC) may reduce hassle costs and/or stigma, which have been found to affect access in the context of other health products. For example, the conversion of nicotine replacement therapies (used for smoking cessation) to OTC status lead to an increase in their use (Keeler et al. 2002). In fact, we observe large increases in marijuana use due to RMLs and evidence of corresponding reductions in alternative medications treating chronic pain (consistent with findings in the literature).

Our findings suggest potentially important benefits to older workers and society at large. Broadly, we show non-trivial improvements in work capacity, which we proxy with WC benefit receipt and various other metrics in our mechanism analysis, among older adults. The ability to work likely has positive benefits to workers themselves due to improved earning capacity, and overall health and life satisfaction. Older workers are at elevated risk of leaving the labor market due to poor health (Dwyer and Mitchell 1999). Keeping workers actively engaged in paid employment can have positive spillovers to Social Security and can reduce costs to employers who will experience reduced WC costs. Similarly, working can increase household income and 
improve health (Coe and Zamarro 2011). Hirth et al. (2003) note how little evidence we have on the relationship between access to medical treatments and labor supply outcomes. Since that paper, a small literature has emerged on the availability of specific prescriptions drugs and labor outcomes (e.g., Thirumurthy, Zivin, and Goldstein (2008); Bütikofer, Cronin, and Skira (2020); Garthwaite (2012); and Bütikofer and Skira (2018)). This paper provides additional evidence about the importance of pain management therapies, in particular those that lie outside of traditional pharmaceuticals, on improving work capacity.

There is a continuing debate in the U.S. on whether and how states should address marijuana legalization. In order to formulate a solution, as the first step, identifying both the harms and benefits followed by the policy change is potentially useful. Previous studies provide several pieces of evidence on the positive or negative effect of marijuana legalization on several outcomes related to individuals' health and well-being. The present study provides empirical evidence on the consequences of marijuana legalization on issues related to the labor market outcomes, in particular, WC claiming of older adults. 
Table 1. Summary statistics

\begin{tabular}{|c|c|c|c|}
\hline Sample: & $\begin{array}{l}\text { All states } \\
\text { (all years) }\end{array}$ & $\begin{array}{c}\text { RML states } \\
\text { (pre-RML years) }\end{array}$ & $\begin{array}{c}\text { Non-RML states } \\
\text { (all years) }\end{array}$ \\
\hline \multicolumn{4}{|l|}{ Outcome } \\
\hline Any WC income (past year) & 0.007 & 0.008 & 0.006 \\
\hline WC income (past year; $\$$ ) & 75.07 & 92.47 & 70.18 \\
\hline \multicolumn{4}{|l|}{ RML policy } \\
\hline RML (lagged one year) & 0.062 & 0 & 0 \\
\hline \multicolumn{4}{|l|}{ State-level characteristics } \\
\hline MML & 0.396 & 0.863 & 0.191 \\
\hline Prescription drug monitoring program & 0.937 & 0.976 & 0.920 \\
\hline Naloxone \& Good Samaritan law & 0.402 & 0.466 & 0.321 \\
\hline Pain clinic management law & 0.247 & 0 & 0.346 \\
\hline Minimum wage (\$) & 8.439 & 8.895 & 8.102 \\
\hline State EITC ratio, & 0.099 & 0.048 & 0.078 \\
\hline Governor Democrat & 0.424 & 0.660 & 0.306 \\
\hline Population (millions) & 1.411 & 2.122 & 1.141 \\
\hline \multicolumn{4}{|l|}{ Individual-level characteristics } \\
\hline Age (years) & 50.99 & 50.85 & 51.03 \\
\hline Male & 0.487 & 0.492 & 0.485 \\
\hline Female & 0.513 & 0.508 & 0.515 \\
\hline White & 0.794 & 0.795 & 0.794 \\
\hline African American & 0.123 & 0.085 & 0.142 \\
\hline Other race & 0.083 & 0.120 & 0.064 \\
\hline Hispanic & 0.143 & 0.184 & 0.123 \\
\hline Less than high school & 0.104 & 0.115 & 0.098 \\
\hline High school & 0.295 & 0.265 & 0.310 \\
\hline Some college & 0.269 & 0.273 & 0.269 \\
\hline College degree or more & 0.332 & 0.347 & 0.323 \\
\hline Observations & 517,351 & 101,202 & 370,990 \\
\hline
\end{tabular}

Notes: Dataset is ASEC 2011 to 2019, which captures WC benefit receipt over the period 2010 to 2018. The sample includes respondents 40 to 62 years. Data are weighted by ASEC survey weights. Dollar values expressed in 2018 dollars. 
Table 2A. Effect of recreational marijuana law passage on marijuana use among adults 26 years and older

\begin{tabular}{lcc}
\hline Outcome: & $\begin{array}{c}\text { Marijuana use in the } \\
\text { past 30 days }\end{array}$ & $\begin{array}{c}\text { Marijuana use in the } \\
\text { past year }\end{array}$ \\
\hline RML (lagged one year) & $0.0185^{* *}$ & $0.0239^{* *}$ \\
& $(0.0075)$ & $(0.0107)$ \\
\hline Mean in RML states, pre-RML & 0.0691 & 0.1073 \\
Counterfactual mean & 0.1035 & 0.1532 \\
Observations & 459 & 459 \\
Data source & NSDUH & NSDUH \\
(years) & $(2010-2018)$ & $(2010-2018)$ \\
\hline
\end{tabular}

Notes: The unit of observation is a state in a year. Data in the public use NSDUH data are reported in two-year averages. We use data averaged over the years 2009-2010, 2010-2011, 2011-2012, 2012-2013, 2013-2014, 20142015, 2016-2017, and 2017-2018. We match the RML data (lagged one year) based on the second year of the twoyear averages, that is: 2010, 2011, 2012, 2013, 2014, 2015, 2016, 2017, and 2018. All regression models are estimated with least squares and control for state characteristics (MML, PDMP, naloxone \& Good Samaritan law, pain management clinic law, minimum wage [\$], EITC ratio, Governor Democrat, and population 26 years and older), individual characteristics (age in years, female, African American, other race, Hispanic ethnicity, high school education, some college education, and college education - averaged to the state-year level), state fixed effects, and year fixed effects. Data are weighted by the state population ages 26 years and older. Standard errors are clustered at the state level and are reported in parentheses.

$* * *, * *, *=$ statistically different from zero at the $1 \%, 5 \%, 10 \%$ level.

Table 2B. Effect of recreational marijuana law passage on marijuana misuse: and prescription drug use Admissions to substance use disorder treatment and prescriptions for medications used to treat chronic pain

\begin{tabular}{lcccc}
\hline \hline $\begin{array}{l}\text { Substance listed at } \\
\text { admission: }\end{array}$ & $\begin{array}{c}\text { Marijuana } \\
\text { primary }\end{array}$ & $\begin{array}{c}\text { Any } \\
\text { marijuana }\end{array}$ & $\begin{array}{c}\text { No } \\
\text { marijuana }\end{array}$ & $\begin{array}{c}\text { Chronic pain } \\
\text { prescriptions }\end{array}$ \\
\hline RML (lagged one year) & -2.31 & -1.72 & -34.49 & $-0.31^{*}$ \\
& $(7.50)$ & $(1.63)$ & $(21.17)$ & $(0.16)$ \\
\hline Mean in RML states, pre- & 24.28 & 6.76 & 108.62 & 3.54 \\
RML & & & & \\
Counterfactual mean & 40.11 & 9.90 & 185.81 & 4.29 \\
Observations & 450 & 450 & 450 & 1,263 \\
$\begin{array}{l}\text { Data source } \\
\text { (years) }\end{array}$ & TEDS & TEDS & TEDS & SDUD \\
\hline
\end{tabular}

Notes: The TEDS sample includes admissions to SUD treatment for which the patient is 40-64 years and the SDUD sample includes prescription fills for pain medications among Medicaid enrollees. The following states have missing years of TEDS data: Georgia (2016, 2017, and 2018); Oregon (2015, 2016, 2017, and 2018); and South Carolina (2014 and 2015). In the SDUD, we exclude Washington DC and Rhode Island along with state-quarteryears that display large swings in reporting, see text for full details. The unit of observation is a state in a year in the TEDS analysis and a state in a quarter in a year in the SDUD analysis. All regression models are estimated with least squares and control for state characteristics (MML, PDMP, naloxone \& Good Samaritan law, pain management clinic law, minimum wage [\$], EITC ratio, Governor Democrat, and population), individual characteristics (age in years, female, African American, other race, Hispanic ethnicity, high school education, some college education, and college education - averaged to the state-year level), state fixed effects, and year fixed effects in the TEDS analysis and quarter-year fixed effects in the SDUD analysis. We also control for Affordable Care Act Medicaid expansion in the SDUD analysis, see text for details. Data are weighted by the state population ages 40-64 in the TEDS analysis and data are weighted by the count of Medicaid enrollees 40-62 in the SDUD analysis. Standard errors are clustered at the state level and are reported in parentheses.

$* * *, * *, *=$ statistically different from zero at the $1 \%, 5 \%, 10 \%$ level. 
Table 3. Effect of recreational marijuana law passage on Workers' Compensation benefit receipt

\begin{tabular}{|c|c|c|c|c|}
\hline Specification: & $(1)$ & $\overline{(2)}$ & $\overline{(3)}$ & $(4)$ \\
\hline \multicolumn{5}{|c|}{ Panel A: Any WC income } \\
\hline RML (lagged one year) & $\begin{array}{c}-0.0014 * * \\
(0.0006) \\
\end{array}$ & $\begin{array}{c}-0.0015^{* *} \\
(0.0006)\end{array}$ & $\begin{array}{c}-0.0018 * * * \\
(0.0007) \\
\end{array}$ & $\begin{array}{c}-0.0017 * * \\
(0.0007) \\
\end{array}$ \\
\hline $\begin{array}{l}\text { RML state proportion, pre- } \\
\text { RML }\end{array}$ & 0.008 & 0.008 & 0.008 & 0.008 \\
\hline Counterfactual proportion & 0.009 & 0.009 & 0.009 & 0.009 \\
\hline Bootstrapped $t$-statistic & -- & -- & -2.2540 & -- \\
\hline Observations & 517,351 & 517,351 & 517,351 & 517,351 \\
\hline \multicolumn{5}{|c|}{ Panel B: WC income } \\
\hline RML (lagged one year) & $\begin{array}{c}-18.89 * * * \\
(6.84)\end{array}$ & $\begin{array}{c}-19.42 * * * \\
(6.73)\end{array}$ & $\begin{array}{c}-21.98 * * * \\
(8.04)\end{array}$ & $\begin{array}{c}-18.63^{*} \\
(9.67)\end{array}$ \\
\hline RML state mean, pre-RML & $\$ 92.47$ & $\$ 92.47$ & $\$ 92.47$ & $\$ 92.47$ \\
\hline Counterfactual mean & $\$ 107.22$ & $\$ 107.22$ & $\$ 107.22$ & $\$ 107.22$ \\
\hline Bootstrapped $t$-statistic & -- & -- & -2.1803 & -- \\
\hline Observations & 517,351 & 517,351 & 517,351 & 517,351 \\
\hline Data are weighted & $\mathrm{Y}$ & $\mathrm{Y}$ & $\mathrm{Y}$ & $\mathrm{N}$ \\
\hline State fixed effects & Y & $\mathrm{Y}$ & $\mathrm{Y}$ & $\mathrm{Y}$ \\
\hline Year fixed effects & $\mathrm{Y}$ & $\mathrm{Y}$ & $\mathrm{Y}$ & $\mathrm{Y}$ \\
\hline Individual controls & $\mathrm{N}$ & Y & $\mathrm{Y}$ & $\mathrm{Y}$ \\
\hline State controls & $\mathrm{N}$ & $\mathrm{N}$ & $\mathrm{Y}$ & $\mathrm{Y}$ \\
\hline
\end{tabular}

Notes: Dataset is ASEC 2011 to 2019, which captures WC benefit receipt over the period 2010 to 2018 . The sample includes respondents 40 to 62 years. The unit of observation is a respondent in state in a year. The any WC regression is estimated with a probit model and average marginal effect is reported. The WC income regression is estimated with least squares. All regression models control for state characteristics (MML, PDMP, naloxone \& Good Samaritan law, pain management clinic law, minimum wage [\$], EITC ratio, Governor Democrat, and population), individual characteristics (age in years, female, African American, other race, Hispanic ethnicity, high school education, some college education, and college education), state fixed effects, and year fixed effects, unless otherwise noted. Data are weighted by ASEC survey weights, unless otherwise noted. Standard errors are clustered at the state level and are reported in parentheses.

$* * *, * *, *=$ statistically different from zero at the $1 \%, 5 \%, 10 \%$ level. 
Table 4A. Effect of recreational marijuana law passage on other labor market outcomes

\begin{tabular}{|c|c|c|c|c|c|}
\hline Outcome: & $\begin{array}{l}\text { Worked } \\
\text { last year }\end{array}$ & $\begin{array}{c}\text { Labor force } \\
\text { participation }\end{array}$ & $\begin{array}{l}\text { Worked } \\
\text { last week }\end{array}$ & $\begin{array}{c}\text { Hours } \\
\text { worked } \\
\text { last week } \\
\text { (uncond.) }\end{array}$ & $\begin{array}{c}\text { Hours } \\
\text { worked } \\
\text { last week } \\
\text { (cond.) } \\
\end{array}$ \\
\hline RML (lagged one year) & $\begin{array}{l}0.0054 * * \\
(0.0025)\end{array}$ & $\begin{array}{c}0.0025 \\
(0.0040) \\
\end{array}$ & $\begin{array}{c}0.0037 \\
(0.0036) \\
\end{array}$ & $\begin{array}{c}0.1508 \\
(0.1303) \\
\end{array}$ & $\begin{array}{l}0.2800^{* * *} \\
(0.1292) \\
\end{array}$ \\
\hline $\begin{array}{l}\text { Prop./mean. RML } \\
\text { states, pre-RML }\end{array}$ & 0.768 & 0.768 & 0.697 & 28.36 & 39.59 \\
\hline $\begin{array}{l}\text { Counterfactual } \\
\text { prop./mean }\end{array}$ & 0.775 & 0.775 & 0.699 & 28.55 & 39.75 \\
\hline Observations & 517,351 & $4,298,723$ & $4,298,723$ & $4,298,723$ & $3,053,812$ \\
\hline $\begin{array}{l}\text { Data source } \\
\text { (years) }\end{array}$ & $\begin{array}{c}\text { ASEC } \\
(2011-2019)\end{array}$ & $\begin{array}{l}\text { Monthly CPS } \\
(2010-2018)\end{array}$ & $\begin{array}{c}\text { Monthly CPS } \\
(2010-2018)\end{array}$ & $\begin{array}{c}\text { Monthly CPS } \\
(2010-2018)\end{array}$ & $\begin{array}{c}\text { Monthly CPS } \\
(2010-2018)\end{array}$ \\
\hline
\end{tabular}

Notes: The sample includes respondents 40 to 62 years. The unit of observation is a respondent in the ASEC, and a respondent in a state in a year-month in the monthly CPS. The regression model is estimated with a probit model and average marginal effect is reported (binary outcome variable) or least squares (continuous outcome variable). All regression models control for state characteristics (MML, PDMP, naloxone \& Good Samaritan law, pain management clinic law, minimum wage [\$], EITC ratio, Governor Democrat, and population), individual characteristics (age in years, female, African American, other race, Hispanic ethnicity, high school education, some college education, and college education), state fixed effects, year fixed effects, and month-fixed effects (only for CPS monthly data). Data are weighted by ASEC survey weights in the ASEC data and monthly CPS survey person weights in the monthly CPS files. Standard errors are clustered at the state level and are reported in parentheses. $* * *, * *, *=$ statistically different from zero at the $1 \%, 5 \%, 10 \%$ level.

Table 4B. Effect of recreational marijuana law passage on the number of establishments

\begin{tabular}{lcc}
\hline \hline Outcome: & $\begin{array}{c}\text { Total } \\
\text { establishments }\end{array}$ & $\begin{array}{c}\text { Marijuana related } \\
\text { establishments } \dagger\end{array}$ \\
\hline RML (lagged one year) & 65.11 & 46.39 \\
& $(90.07)$ & $(48.72)$ \\
\hline Mean in RML states, pre-RML & 14,436 & 6,381 \\
Counterfactual mean & 15,262 & 6,486 \\
Observations & 459 & 459 \\
Data source & CBP & CBP \\
Years & $2010-2018$ & $2010-2018$ \\
\hline
\end{tabular}

Notes: The outcome is establishment per 100,000 people. The unit of observation is a state in a year. All regression models are estimated with least squares and control for state characteristics (age in years, female, African American, other race, Hispanic ethnicity, high school education, some college education, and college education), state policies (MML, PDMP, naloxone \& Good Samaritan law, pain management clinic law, minimum wage [\$], EITC ratio, Governor Democrat, and population - averaged to the state-year), state fixed effects, and year fixed effects. Data are weighted by the state population. Standard errors are clustered at the state level and are reported in parentheses. $\dagger$ Marijuana related establishments are defined as the following two-digit NAICS codes: Natural Resources and Mining (11), Construction (23), Manufacturing (31-33), Trade (42, 44-45), Information (51), Financial Activities (52), Education (61), and Health Services (62). See text for details. $* * *, * *, *=$ statistically different from zero at the $1 \%, 5 \%, 10 \%$ level. 
Table 5. Effect of recreational marijuana law passage on injury outcomes

\begin{tabular}{lcccc}
\hline \hline Outcome: & $\begin{array}{c}\text { Non-fatal } \\
\text { injury }\end{array}$ & $\begin{array}{c}\text { Non-fatal injury } \\
\text { (traumatic) }\end{array}$ & $\begin{array}{c}\text { Non-fatal injury } \\
\text { (non-traumatic) }\end{array}$ & $\begin{array}{c}\text { Predicted } \\
\text { injury rate }\end{array}$ \\
\hline RML (lagged one year) & $-32.49^{* * *}$ & $-25.39^{* *}$ & $-7.10^{* * *}$ & -20.12 \\
& $(11.42)$ & $(10.82)$ & $(1.82)$ & $(24.83)$ \\
\hline Mean in RML states, pre- & 518.48 & 493.12 & 25.36 & 687.97 \\
RML & & & & \\
Counterfactual mean & 600.54 & 570.18 & 30.36 & 844.41 \\
Observations & 337 & 337 & 337 & 344 \\
Data source & BLS SOII & BLS SOII & BLS SOII & ASEC \\
Years & $(2011-2018)$ & $(2011-2018)$ & $(2011-2018)$ & $(2011-2018)$ \\
\hline
\end{tabular}

Notes: The BLS SOII sample includes injuries among those 40 to 62 years and the ASEC sample includes respondents ages 40 to 62 years. The unit of observation is a state in a year, the ASEC data are aggregated from the microdata (respondent in a state in a year) to the state-year level. There are ten states with missing data in the BLS data, full details available on request (see Appendix Table 5A for corresponding WC results for this same sample). All regression models are estimated with least squares and control for state characteristics (age in years, female, African American, other race, Hispanic ethnicity, high school education, some college education, and college education - averaged to the state-year level), state policies (MML, PDMP, naloxone \& Good Samaritan law, pain management clinic law, minimum wage [\$], EITC ratio, Governor Democrat, and population), state fixed effects, and year fixed effects. Data are weighted by the state population 40 to 62 . Standard errors are clustered at the state level and are reported in parentheses.

$* * *, * *, *=$ statistically different from zero at the $1 \%, 5 \%, 10 \%$ level. 
Table 6. Effect of recreational marijuana law passage on health outcomes

\begin{tabular}{lccc}
\hline \hline Outcome: & $\begin{array}{c}\text { Good/very } \\
\text { good/excellent health }\end{array}$ & $\begin{array}{c}\text { Work limiting } \\
\text { disability }\end{array}$ & $\begin{array}{c}\text { Absent from work due } \\
\text { to own health } \dagger\end{array}$ \\
\hline RML (lagged one year) & -0.0050 & $-0.0068^{* * *}$ & 0.0006 \\
& $(0.0082)$ & $(0.0020)$ & $(0.0004)$ \\
\hline Prop. in RML states, pre- & 0.886 & 0.111 & 0.0081 \\
RML & & & \\
Counterfactual prop. & 0.849 & 0.109 & 0.0075 \\
Observations & 517,351 & 517,351 & $3,078,174$ \\
$\begin{array}{l}\text { Data source } \\
\text { (years) }\end{array}$ & ASEC & ASEC & Monthly CPS \\
\hline
\end{tabular}

Notes: The sample includes respondents 40 to 62 years. The unit of observation is a respondent in state in a year in the ASEC, and a respondent in a state in a year-month in the monthly CPS. All regression models are estimated with a probit model (average marginal effect reported) and control for state characteristics (MML, PDMP, naloxone \& Good Samaritan law, pain management clinic law, minimum wage [\$], EITC ratio, Governor Democrat, and population), individual characteristics (age in years, female, African American, other race, Hispanic ethnicity, high school education, some college education, and college education), state fixed effects, and year fixed effects. The ASEC regression models also control for individual characteristics. Data are weighted by ASEC survey weights in the ASEC data and monthly CPS survey person weights in the monthly CPS files. Standard errors are clustered at the state level and are reported in parentheses.

$\dagger$ Absent from work due to health is defined as reporting being absent from work in the past week due to own illness/injury/medical problems.

$* * *, * *, *=$ statistically different from zero at the $1 \%, 5 \%, 10 \%$ level. 
Figure 1A. Workers' Compensation claiming costs in the U.S.: 2010 to 2018

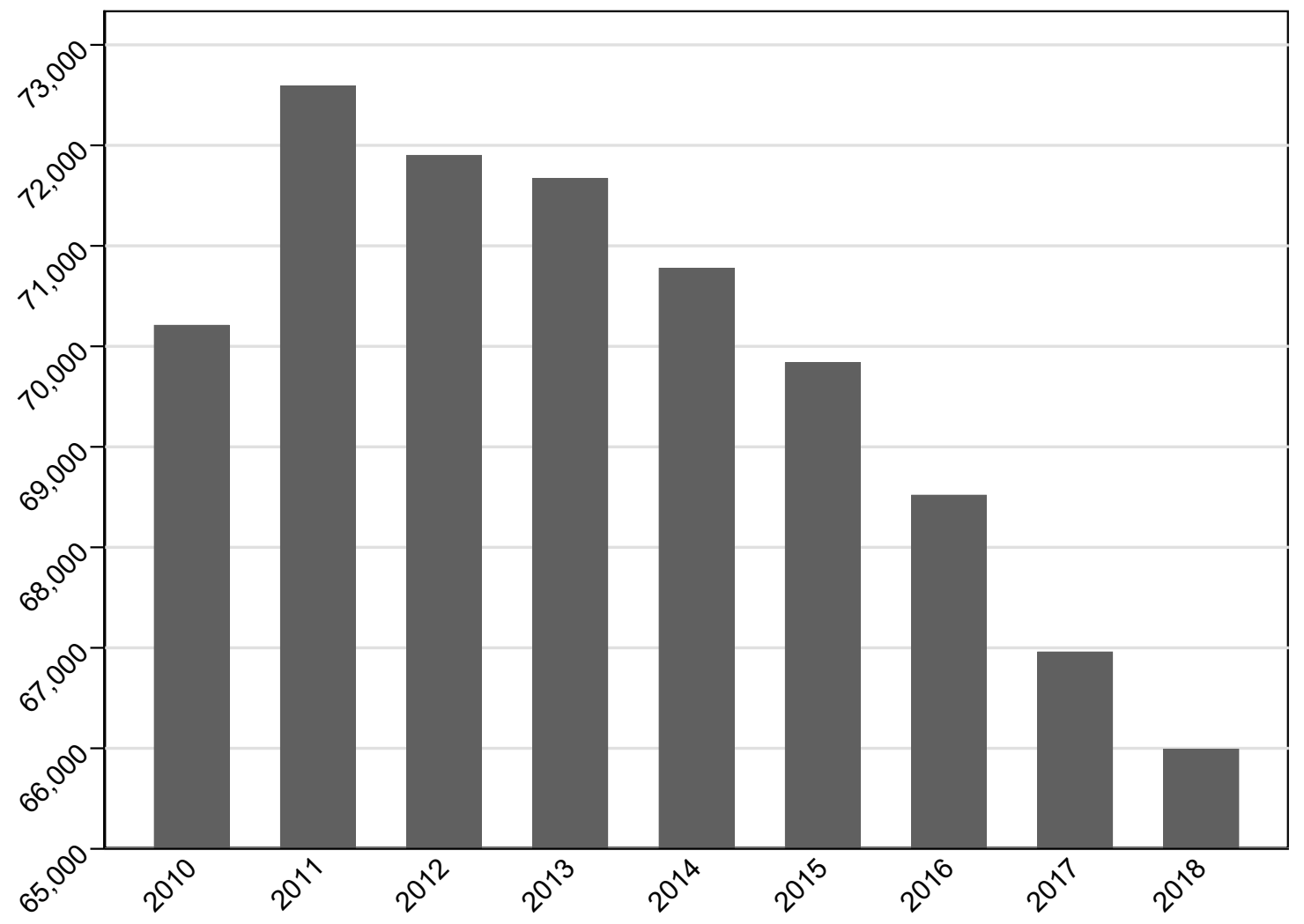

Notes: The figure is based on Table 5 in Weiss et al (2020). The most recent year of data available at the time of writing is 2018. We inflate nominal values to 2020 dollars using the Consumer Price Index. See text for details. 
Figure 1B. RML adoptions and announcements by December 2020

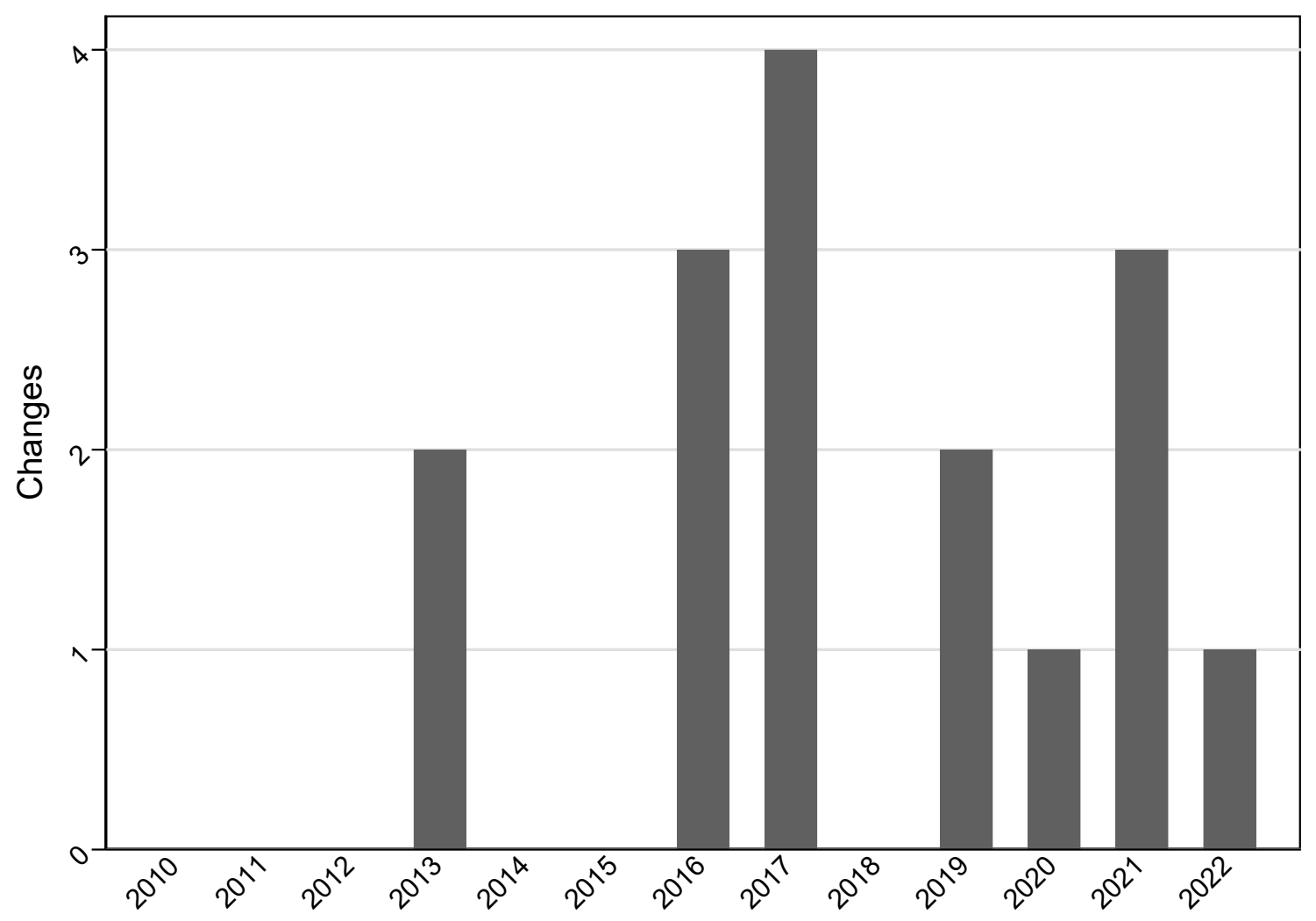

Notes: The figure is based on data reported in Chan et al (2019) and ProCon.org (2020). Note that law changes are coded as of January $1^{\text {st }}$ of each year. RML effective dates (adopted or announced by December, 2020) are as follows: Alaska: February 2015, Arizona: November 2020; California: November 2016, Colorado: December 2012, District of Columbia: February 2015, Illinois: January 2020, Maine: January 2017, Massachusetts: December 2016, Michigan December 2018, Montana: January 2021, Nevada: January 2017, New Jersey January 2021, Oregon: July 2015, South Dakota: July 2021, Vermont: July 2018, and Washington: November 2012. See text for details. 
Figure 2. States with an RML implemented or announced by December 2020

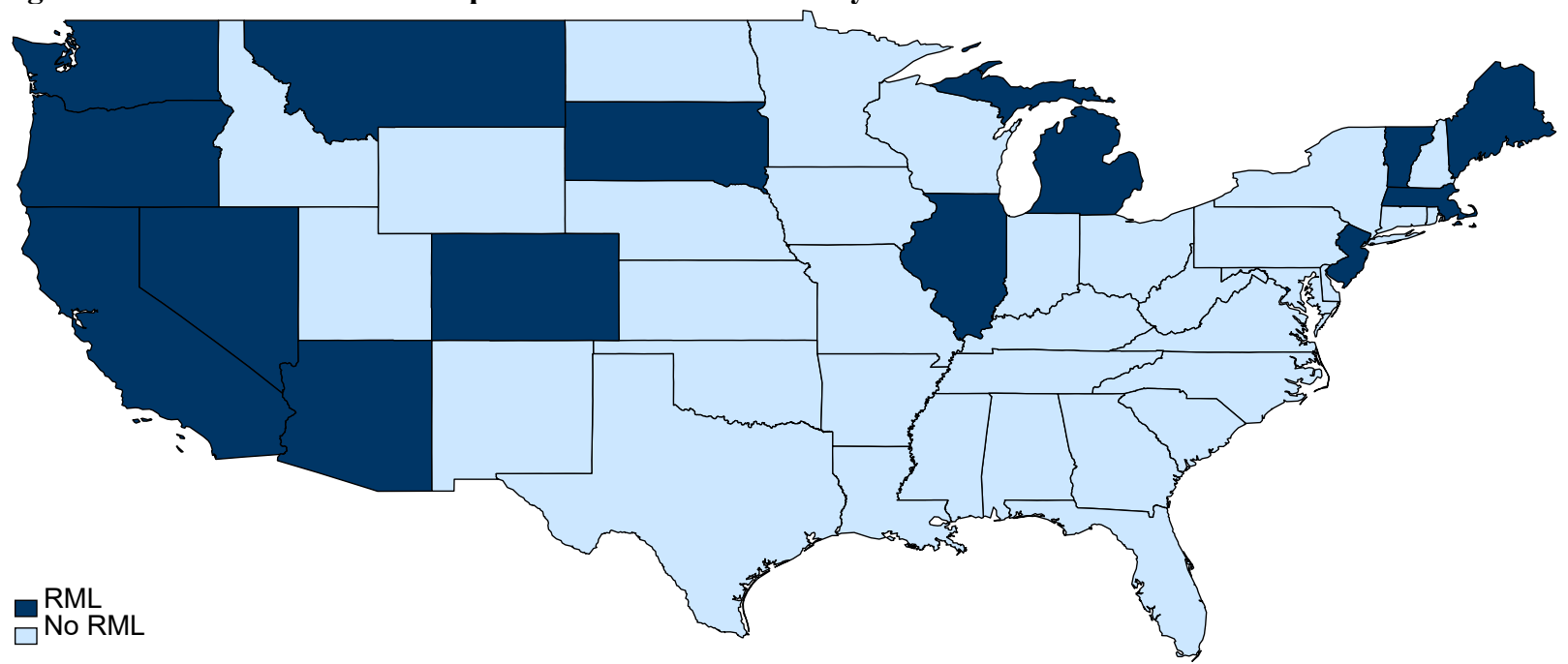

Notes: The figure is based on data reported in Chan et al (2019) and ProCon.org (2020). Note that law changes are coded as of January $1^{\text {st }}$ of each year. RML effective dates (adopted or announced by December, 2020) are as

follows: Alaska: February 2015, Arizona: November 2020; California: November 2016, Colorado: December 2012, District of Columbia: February 2015, Illinois: January 2020, Maine: January 2017, Massachusetts: December 2016, Michigan December 2018, Montana: January 2021, Nevada: January 2017, New Jersey January 2021, Oregon: July 2015, South Dakota: July 2021, Vermont: July 2018, and Washington: November 2012. See text for details. 
Figure 3. The effect of recreational marijuana law passage on Workers' Compensation benefit receipt: Event study analysis

Panel A: Any WC income

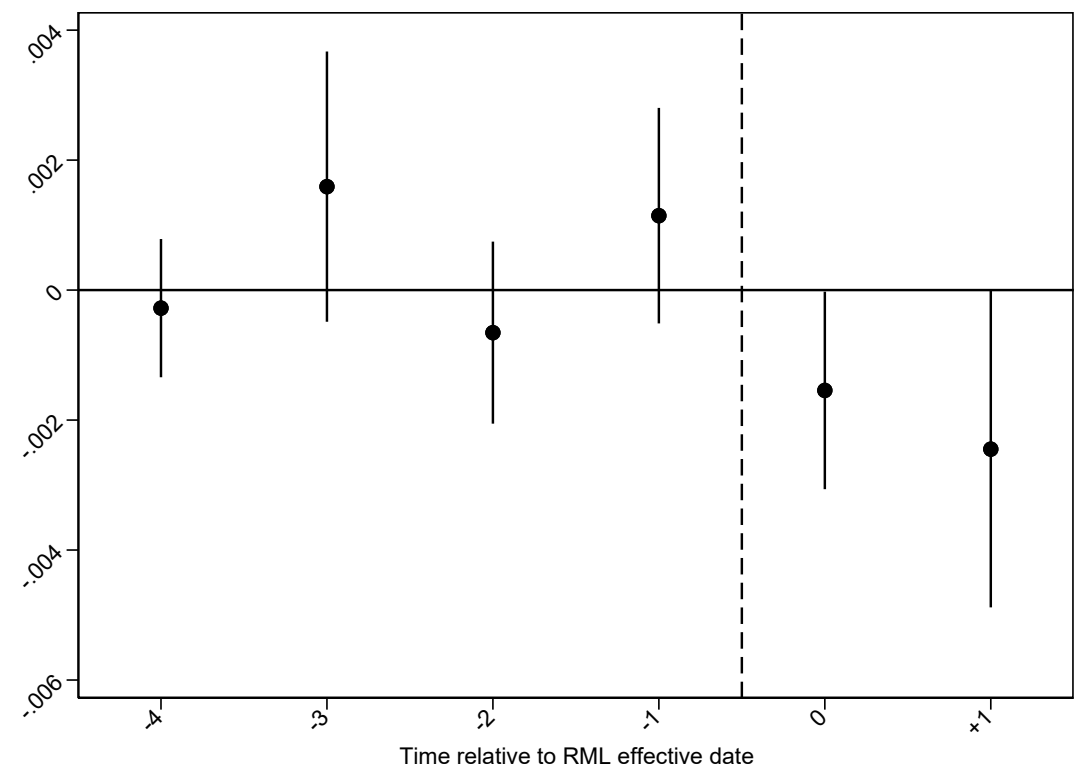

Panel B: WC income

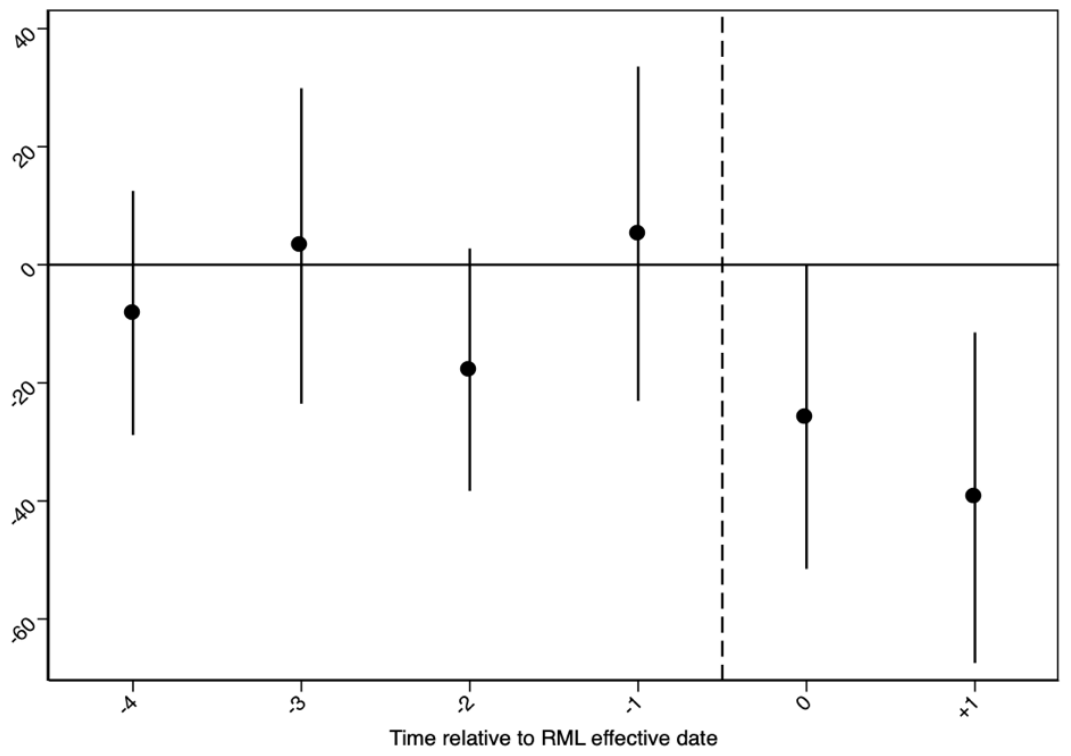

Notes: Dataset is ASEC 2011 to 2019, which captures WC benefit receipt over the period 2010 to 2018. The sample includes respondents 40 to 62 years. The unit of observation is a respondent in state in a year. Circles represent coefficient estimates and $95 \%$ confidence intervals are depicted by vertical lines. The regression is estimated with a probit model and average marginal effects are reported when the outcome is binary and least squares when the outcome is continuous. The omitted category is five or more years pre-RML passage. States that do not adopt an RML are coded as zero for all event-time indicators. The regression model controls for state characteristics (MML, PDMP, naloxone \& Good Samaritan law, pain management clinic law, minimum wage [\$], EITC ratio, Governor Democrat, and population), individual characteristics (age in years, female, African American, other race, Hispanic ethnicity, high school education, some college education, and college education), state fixed effects, and year fixed effects. Data are weighted by ASEC survey weights. Confidence intervals are clustered at the state level. 
Figure 4. The effect of recreational marijuana law passage on Workers' Compensation benefit receipt: Falsification exercise

Panel A: Any WC income

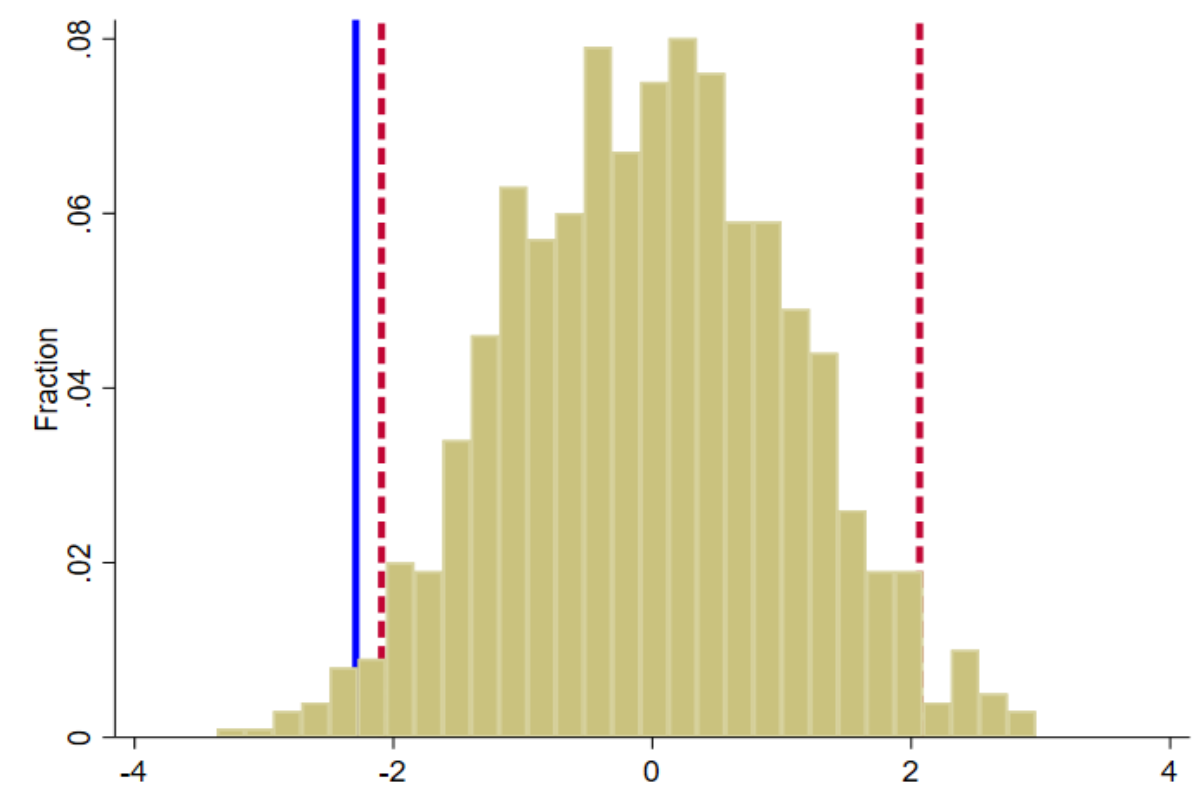

Panel B: WC income

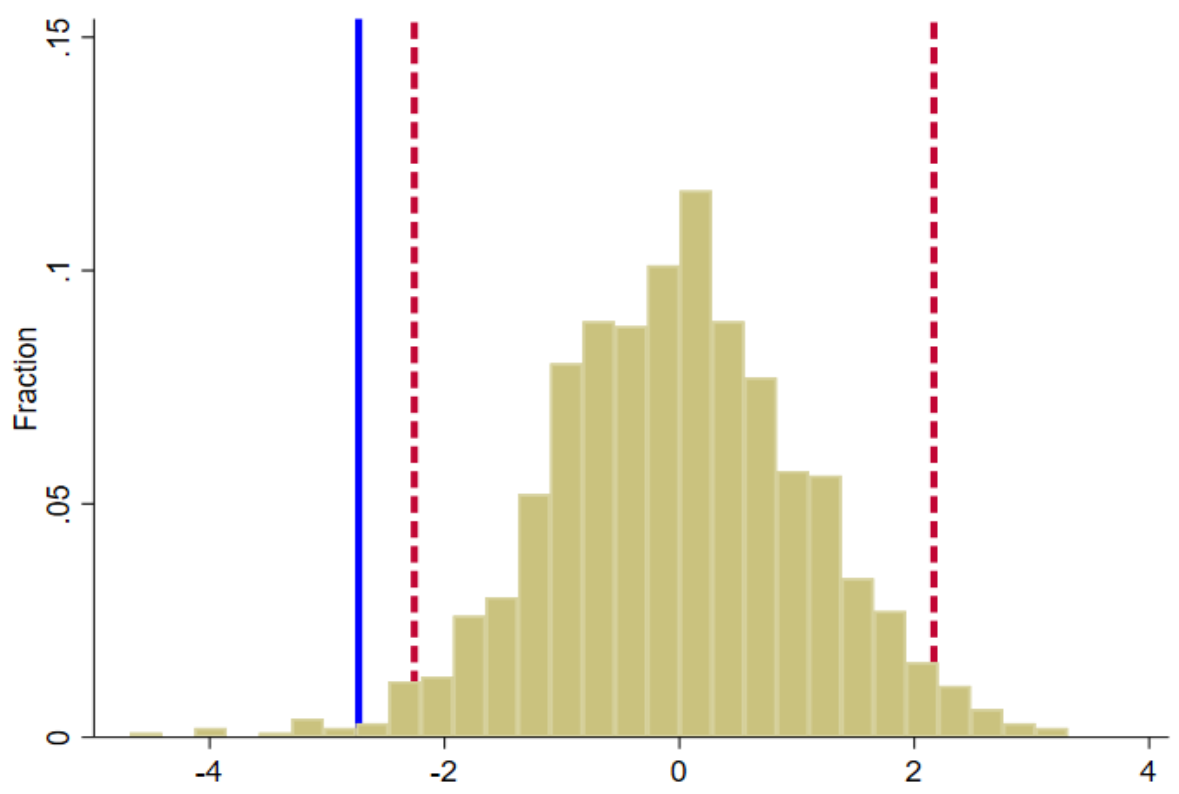

Notes: Dataset is ASEC 2011 to 2019, which captures WC benefit receipt over the period 2010 to 2018. The sample includes respondents 40 to 62 years. The unit of observation is a respondent in state in a year. All regression models are estimated with a probit model (average marginal effects reported) when the outcome is binary, and least squares when the outcome is continuous and control for state characteristics (MML, PDMP, naloxone \& Good Samaritan law, pain management clinic law, minimum wage [\$], EITC ratio, Governor Democrat, and population), individual characteristics (age in years, female, African American, other race, Hispanic ethnicity, high school education, some college education, and college education), state fixed effects, and year fixed effects. Data are weighted by ASEC survey weights. The $\mathrm{x}$-axis reports the $t$-statistic value. We randomly assign states into treatment status, holding constant the number of states adopting in each year. The 'true' $t$-statistic is the solid blue line. The red dotted lines are the 2.5 and 97.5 percentiles of the placebo $t$-statistics. See text for more details. 
Appendix Table 1. Effect of recreational marijuana law passage on Workers' Compensation benefit receipt: All coefficient estimates

\begin{tabular}{|c|c|c|}
\hline Outcome: & Any WC income & WC income \\
\hline RML (lagged one year) & $\begin{array}{c}-0.0018^{* * *} \\
(0.0007)\end{array}$ & $\begin{array}{c}-21.98^{* * *} \\
(8.04)\end{array}$ \\
\hline \multicolumn{3}{|l|}{ Other controls } \\
\hline MML & $\begin{array}{c}-0.0010 \\
(0.0006)\end{array}$ & $\begin{array}{l}-0.97 \\
(9.67)\end{array}$ \\
\hline Prescription drug monitoring program & $\begin{array}{l}-0.0006 \\
(0.0007)\end{array}$ & $\begin{array}{l}-13.51 \\
(8.26)\end{array}$ \\
\hline Naloxone \& Good Samaritan law & $\begin{array}{l}-0.0004 \\
(0.0005)\end{array}$ & $\begin{array}{c}-12.46^{*} \\
(7.04)\end{array}$ \\
\hline Pain management clinic law & $\begin{array}{c}0.0002 \\
(0.0008)\end{array}$ & $\begin{array}{c}10.85 \\
(11.41)\end{array}$ \\
\hline Minimum wage (\$) & $\begin{array}{c}0.0004 \\
(0.0003)\end{array}$ & $\begin{array}{c}5.63 \\
(5.54)\end{array}$ \\
\hline State EITC ratio & $\begin{array}{l}-0.0001 \\
(0.0007)\end{array}$ & $\begin{array}{c}-9.97 \\
(10.60)\end{array}$ \\
\hline Governor Democrat & $\begin{array}{l}-0.0000 \\
(0.0005)\end{array}$ & $\begin{array}{c}0.71 \\
(6.86)\end{array}$ \\
\hline Population & $\begin{array}{l}-0.0000^{*} \\
(0.0000)\end{array}$ & $\begin{array}{l}-0.00 \\
(0.00)\end{array}$ \\
\hline Age (in years) & $\begin{array}{c}0.0001^{* * * *} \\
(0.000)\end{array}$ & $\begin{array}{c}2.06^{* * *} \\
(0.42)\end{array}$ \\
\hline Female & $\begin{array}{c}-0.0024 * * * \\
(0.0004)\end{array}$ & $\begin{array}{c}-42.29^{* * *} \\
(4.65)\end{array}$ \\
\hline African American & $\begin{array}{c}0.0006 \\
(0.0005)\end{array}$ & $\begin{array}{l}-0.07 \\
(5.86)\end{array}$ \\
\hline Other race & $\begin{array}{l}-0.0005 \\
(0.0005)\end{array}$ & $\begin{array}{c}0.09 \\
(8.14)\end{array}$ \\
\hline Hispanic ethnicity & $\begin{array}{c}0.0000 \\
(0.0000)\end{array}$ & $\begin{array}{c}2.22 \\
(9.73)\end{array}$ \\
\hline High school & $\begin{array}{c}0.0002 \\
(0.0006)\end{array}$ & $\begin{array}{l}11.38 \\
(9.23)\end{array}$ \\
\hline Some college & $\begin{array}{l}-0.0000 \\
(0.0006)\end{array}$ & $\begin{array}{c}11.39 \\
(12.71)\end{array}$ \\
\hline College degree or more & $\begin{array}{c}-0.0065^{* * *} \\
(0.0005)\end{array}$ & $\begin{array}{c}-53.48 * * * \\
(10.66)\end{array}$ \\
\hline RML state prop./mean, pre-RML & 0.008 & $\$ 92.47$ \\
\hline Counterfactual prop./mean & 0.009 & 107.22 \\
\hline Observations & 517,351 & 517,351 \\
\hline
\end{tabular}

Notes: Dataset is ASEC 2011 to 2019, which captures WC benefit receipt over the period 2010 to 2018. The sample includes respondents 40 to 62 years. The unit of observation is a respondent in state in a year. The any WC regression is estimated with a probit model and average marginal effect is reported. The WC income regression is estimated with least squares. All regression models control for state fixed effects and year fixed effects. Omitted categories are male (sex), white (race), non-Hispanic (ethnicity), and less than high school (education). Data are weighted by ASEC survey weights. Standard errors are clustered at the state level and are reported in parentheses. $* * *, * *, *=$ statistically different from zero at the $1 \%, 5 \%, 10 \%$ level. 
Appendix Table 2. State-level correlates predicting adoption of a recreational marijuana law

\begin{tabular}{|c|c|}
\hline Outcome: & RML \\
\hline MML & $\begin{array}{l}-0.0253 \\
(0.0483)\end{array}$ \\
\hline Prescription drug monitoring program & $\begin{array}{l}-0.0161 \\
(0.0485)\end{array}$ \\
\hline Naloxone \& Good Samaritan law & $\begin{array}{c}0.0944 * * \\
(0.0367)\end{array}$ \\
\hline Pain management clinic & $\begin{array}{c}0.0915 \\
(0.0569)\end{array}$ \\
\hline Minimum wage & $\begin{array}{c}0.1436 * * * \\
(0.0454)\end{array}$ \\
\hline State EITC ratio & $\begin{array}{l}0.5483 * \\
(0.3191)\end{array}$ \\
\hline Governor Democrat & $\begin{array}{l}-0.0166 \\
(0.0542)\end{array}$ \\
\hline Population & $\begin{array}{l}-0.0000 \\
(0.0000)\end{array}$ \\
\hline Age & $\begin{array}{l}-0.0445 \\
(0.0587)\end{array}$ \\
\hline Female & $\begin{array}{c}0.0032 \\
(1.4295)\end{array}$ \\
\hline African American & $\begin{array}{c}-0.5370 * * \\
(0.2560)\end{array}$ \\
\hline Other race & $\begin{array}{c}0.1263 \\
(0.3592)\end{array}$ \\
\hline Hispanic & $\begin{array}{c}-0.0020 * * \\
(0.0009)\end{array}$ \\
\hline High school & $\begin{array}{l}-1.0327 \\
(0.6888)\end{array}$ \\
\hline Some college & $\begin{array}{l}-0.2527 \\
(0.5892)\end{array}$ \\
\hline College degree or more & $\begin{array}{c}-0.7246 \\
(0.6562) \\
\end{array}$ \\
\hline $\begin{array}{l}F \text {-test of joint significance of time-varying variables } \\
\text { ( } p \text {-value) } \\
\text { Mean proportion } \\
\text { Observations }\end{array}$ & $\begin{array}{c}23.15 \\
(<0.000) \\
0.083 \\
459\end{array}$ \\
\hline
\end{tabular}

Notes: The unit of observation is a state in a year. The regression model is estimated with least squares and controls for state characteristics, state fixed effects, and year fixed effects. Omitted categories are male (sex), white (race), non-Hispanic (ethnicity), and less than high school (education). Note that we aggregate the demographics from the respondent-state-year to the state-year level, applying ASEC weights in the aggregation. Data are weighted by the state population. Standard errors are clustered at the state level and are reported in parentheses.

$* * *, * *, *=$ statistically different from zero at the $1 \%, 5 \%, 10 \%$ level. 
Appendix Table 3. Effect of recreational marijuana law passage on Workers' Compensation benefit receipt: Add time-varying controls one at a time

\begin{tabular}{|c|c|c|}
\hline Outcome: & Any WC income & WC income \\
\hline \multicolumn{3}{|l|}{ Panel A: Baseline model } \\
\hline RML (lagged one year) & $\begin{array}{c}-0.0018^{* * *} \\
(0.0007)\end{array}$ & $\begin{array}{c}-21.98^{* * *} \\
(8.04)\end{array}$ \\
\hline \multicolumn{3}{|l|}{ Panel B: Progressively add control variables } \\
\hline Added control: MML & $\begin{array}{c}-0.0015^{* *} \\
(0.0006)\end{array}$ & $\begin{array}{c}-19.14 * * * \\
(6.95)\end{array}$ \\
\hline Added control: Prescription drug monitoring program & $\begin{array}{c}-0.0015^{* *} \\
(0.0006)\end{array}$ & $\begin{array}{c}-19.24 * * * \\
(6.84)\end{array}$ \\
\hline Added control: Naloxone \& Good Samaritan law & $\begin{array}{c}-0.0015^{* *} \\
(0.0006)\end{array}$ & $\begin{array}{c}-19.95 * * * \\
(6.92)\end{array}$ \\
\hline Added control: Pain management clinic & $\begin{array}{c}-0.0015^{* *} \\
(0.0006)\end{array}$ & $\begin{array}{c}-18.65 * * \\
(7.02)\end{array}$ \\
\hline Added control: Minimum wage & $\begin{array}{c}-0.0018 * * * \\
(0.0006)\end{array}$ & $\begin{array}{c}-24.31 * * * \\
(8.13)\end{array}$ \\
\hline Added control: State EITC ratio & $\begin{array}{c}-0.0016^{* *} \\
(0.0007)\end{array}$ & $\begin{array}{c}-21.59 * * \\
(8.28)\end{array}$ \\
\hline Added control: Governor Democrat & $\begin{array}{c}-0.0016^{* *} \\
(0.0007)\end{array}$ & $\begin{array}{c}-21.58^{* *} \\
(8.17)\end{array}$ \\
\hline Added control: Population & $\begin{array}{c}-0.0017 * * \\
(0.0007)\end{array}$ & $\begin{array}{c}-21.62 * * \\
(8.16)\end{array}$ \\
\hline Added control: Age & $\begin{array}{c}-0.0017 * * \\
(0.0007)\end{array}$ & $\begin{array}{c}-21.87 * * \\
(8.33)\end{array}$ \\
\hline Added control: Female & $\begin{array}{c}-0.0017 * * \\
(0.0007)\end{array}$ & $\begin{array}{c}-21.54 * * \\
(8.16)\end{array}$ \\
\hline Added control: African American & $\begin{array}{c}-0.0017 * * \\
(0.0007)\end{array}$ & $\begin{array}{c}-21.52^{* * *} \\
(8.16)\end{array}$ \\
\hline Added control: Other race & $\begin{array}{c}-0.0017 * * \\
(0.0007)\end{array}$ & $\begin{array}{c}-21.55^{* *} \\
(8.16)\end{array}$ \\
\hline Added control: Hispanic & $\begin{array}{c}-0.0017^{* *} \\
(0.0007)\end{array}$ & $\begin{array}{c}-21.63 * * \\
(8.17)\end{array}$ \\
\hline Added control: High school & $\begin{array}{c}-0.0017 * * \\
(0.0007)\end{array}$ & $\begin{array}{c}-21.97 * * * \\
(8.13)\end{array}$ \\
\hline Added control: Some college & $\begin{array}{c}-0.0017 * * \\
(0.0007)\end{array}$ & $\begin{array}{c}21.98 * * * \\
(8.04)\end{array}$ \\
\hline Added control: College degree or more & $\begin{array}{c}-0.0018 * * * \\
(0.0007) \\
\end{array}$ & $\begin{array}{c}-21.98^{* * *} \\
(8.04) \\
\end{array}$ \\
\hline RML state prop./mean, pre-RML & 0.008 & $\$ 92.47$ \\
\hline Counterfactual prop./mean & 0.009 & 107.22 \\
\hline Observations & 517,351 & 517,351 \\
\hline
\end{tabular}

Notes: Dataset is ASEC 2011 to 2019, which captures WC benefit receipt over the period 2010 to 2018. The sample includes respondents 40 to 62 years. The unit of observation is a respondent in state in a year. The any WC regression is estimated with a probit model and average marginal effect is reported. The WC income regression is estimated with least squares. The baseline model controls for state characteristics (MML, PDMP, naloxone \& Good Samaritan law, pain management clinic law, minimum wage [\$], EITC ratio, Governor Democrat, and population), individual characteristics (age in years, female, African American, other race, Hispanic ethnicity, high school education, some college education, and college education), state fixed effects, and year fixed effects. Omitted categories are male (sex), white (race), non-Hispanic (ethnicity), and less than high school (education). Each row in Panel B progressively adds time-varying controls to the regression model. Data are weighted by ASEC survey weights. Standard errors are clustered at the state level and are reported in parentheses.

$* * *, * *, *=$ statistically different from zero at the $1 \%, 5 \%, 10 \%$ level. 
Appendix Table 4. Effect of recreational marijuana law passage on migration into and out of states

\begin{tabular}{lccc}
\hline \hline Outcome: & Any migration & Migrate in & Migrate out \\
\hline RML (lagged one year) & -0.0003 & -0.0012 & 0.0005 \\
& $(0.0000)$ & $(0.0010)$ & $(0.0000)$ \\
\hline Proportion in RML states, pre-RML & 0.011 & 0.008 & 0.003 \\
Counterfactual proportion & 0.012 & 0.012 & 0.004 \\
Observations & 517,351 & 517,351 & 517,351 \\
\hline
\end{tabular}

Notes: Dataset is ASEC 2011 to 2019. The sample includes respondents 40 to 62 years. The unit of observation is a respondent in state in a year. All regression models estimated with a probit model (average marginal effects reported) and control for state characteristics (MML, PDMP, naloxone \& Good Samaritan law, pain management clinic law, minimum wage [\$], EITC ratio, Governor Democrat, and population), individual characteristics (age in years, female, African American, other race, Hispanic ethnicity, high school education, some college education, and college education), state fixed effects, and year fixed effects. Data are weighted by ASEC survey weights. Standard errors are clustered at the state level and are reported in parentheses.

$* * *, * *, *=$ statistically different from zero at the $1 \%, 5 \%, 10 \%$ level. 
Appendix Table 5A. Effect of recreational marijuana law passage on Workers' Compensation benefit receipt, alternative specifications and samples

\begin{tabular}{|c|c|c|}
\hline Outcome: & Any WC income & WC income \\
\hline \multicolumn{3}{|c|}{ Panel A: Include state-specific linear time trends } \\
\hline RML (lagged one year) & $-0.0020 * *$ & -14.95 \\
\hline & $(0.0010)$ & $(13.17)$ \\
\hline Observations & 517,351 & 517,351 \\
\hline \multicolumn{3}{|c|}{ Panel B: Include region-by-year fixed effects } \\
\hline RML (lagged one year) & -0.0014 & $-16.50 *$ \\
\hline & $(0.0009)$ & $(8.37)$ \\
\hline Observations & 517,351 & 517,351 \\
\hline \multicolumn{3}{|c|}{ Panel C: Exclude state-year pairs with no TEDS admissions data } \\
\hline RML (lagged one year) & $-0.0018 * *$ & $-21.11 * *$ \\
\hline & $(0.0008)$ & $(8.44)$ \\
\hline Observations & 509,627 & 509,627 \\
\hline \multicolumn{3}{|c|}{ Panel D: Exclude states-year pairs with no BLS SOII injury data } \\
\hline RML (lagged one year) & $-0.0016 * *$ & $-16.85 * *$ \\
\hline & $(0.0008)$ & $(7.78)$ \\
\hline Observations & 38,4673 & 384,673 \\
\hline \multicolumn{3}{|c|}{ Panel E: Use current RML } \\
\hline RML (current year) & $-0.0024 * * *$ & $-27.27 * *$ \\
\hline & $(0.0008)$ & $(10.65)$ \\
\hline Observations & 517,351 & 517,351 \\
\hline \multicolumn{3}{|c|}{ Panel F: Include industry fixed effects } \\
\hline RML (lagged one year) & $-0.0020 * *$ & $-22.03 * * *$ \\
\hline & $(0.0009)$ & $(7.91)$ \\
\hline Observations & 517,351 & 517,351 \\
\hline \multicolumn{3}{|c|}{ Panel G: Include occupation fixed effects } \\
\hline RML (lagged one year) & $-0.0020 * *$ & $-21.78 * * *$ \\
\hline & $(0.0008)$ & $(8.03)$ \\
\hline Observations & 517,351 & 517,351 \\
\hline \multicolumn{3}{|c|}{ Panel H: Aggregate data to the state-year level $\uparrow$} \\
\hline RML (lagged one year) & $-0.0015^{*}$ & $-20.15^{*}$ \\
\hline & $(0.0008)$ & $(11.33)$ \\
\hline Observations & 459 & 459 \\
\hline \multicolumn{3}{|c|}{ Panel I: Control for state-level WC policy variables } \\
\hline RML (lagged one year) & $-0.0019 * *$ & $-31.88 * * *$ \\
\hline & $(0.009)$ & $(9.77)$ \\
\hline Observations & 517,351 & 517,351 \\
\hline \multicolumn{3}{|c|}{ Panel J: Allow for heterogeneous treatment effects across states and time } \\
\hline RML (lagged one year) & $-0.0016^{*}$ & $-16.73 * *$ \\
\hline & $(0.0009)$ & $(9.02)$ \\
\hline Observations & 517,351 & 517,351 \\
\hline Prop./mean in RML states, pre-RML†† & 0.008 & $\$ 92.47$ \\
\hline Counterfactual prop./mean & 0.009 & $\$ 107.22$ \\
\hline
\end{tabular}

Notes: Dataset is ASEC 2011 to 2019, which captures WC benefit receipt over the period 2010 to 2018 . The unit of observation is a respondent in state in a year. All regression models estimated with a probit model (average marginal effects reported) when the outcome is binary and least squares when the outcome is continuous, and control for state characteristics (MML, PDMP, naloxone \& Good Samaritan law, pain management clinic law, minimum wage [\$], EITC ratio, Governor Democrat, and population), individual characteristics (age in years, female, African American, other race, Hispanic ethnicity, high school education, some college education, and college education), state fixed effects, and year fixed effects, unless otherwise noted. Data are weighted by ASEC survey weights. Standard errors are clustered at the state level and are reported in parentheses.

$* * *, * * *=$ statistically different from zero at the $1 \%, 5 \%, 10 \%$ level.

$\dagger$ Data are aggregated to the state-year level. The unit of observation is a state in a year. 
$\dagger \dagger$ Counterfactual proportions and means are based on the full sample. 
Appendix Table 5B. Effect of recreational marijuana law passage on Workers' Compensation benefit receipt, alternative specifications of the regression model

\begin{tabular}{lcc}
\hline \hline Outcome: & Any WC income & WC income \\
\hline Column: & $(1)$ & $(2)$ \\
Regression model: & Linear probability model & Poisson \\
\hline RML (lagged one year) & $-0.0021^{* *}$ & $-16.29^{* *}$ \\
& $(0.0009)$ & $(7.61)$ \\
\hline Prop./mean in RML states, pre-RML & 0.008 & $\$ 92.47$ \\
Counterfactual prop./mean & 0.009 & $\$ 102.67$ \\
Observations & 517,351 & 517,351 \\
\hline Notes: Dataset is ASEC 2011 to 2019, which captures WC benefit receipt over the period 2010 to 2018. The unit of \\
observation is a respondent in state in a year. Marginal effects reported for the Poisson model. All regression \\
models control for state characteristics (MML, PDMP, naloxone \& Good Samaritan law, pain management clinic \\
law, minimum wage [\$], EITC ratio, Governor Democrat, and population), individual characteristics (age in years, \\
female, African American, other race, Hispanic ethnicity, high school education, some college education, and \\
college education), state fixed effects, and year fixed effects unless otherwise noted. Data are weighted by ASEC \\
survey weights. Standard errors are clustered at the state level and are reported in parentheses. \\
$* * *, * * *$ = statistically different from zero at the 1\%,5\%,10\% level.
\end{tabular}


Appendix Table 6. Effect of recreational marijuana law passage on Workers' Compensation benefit receipt, allowing for dispensaries

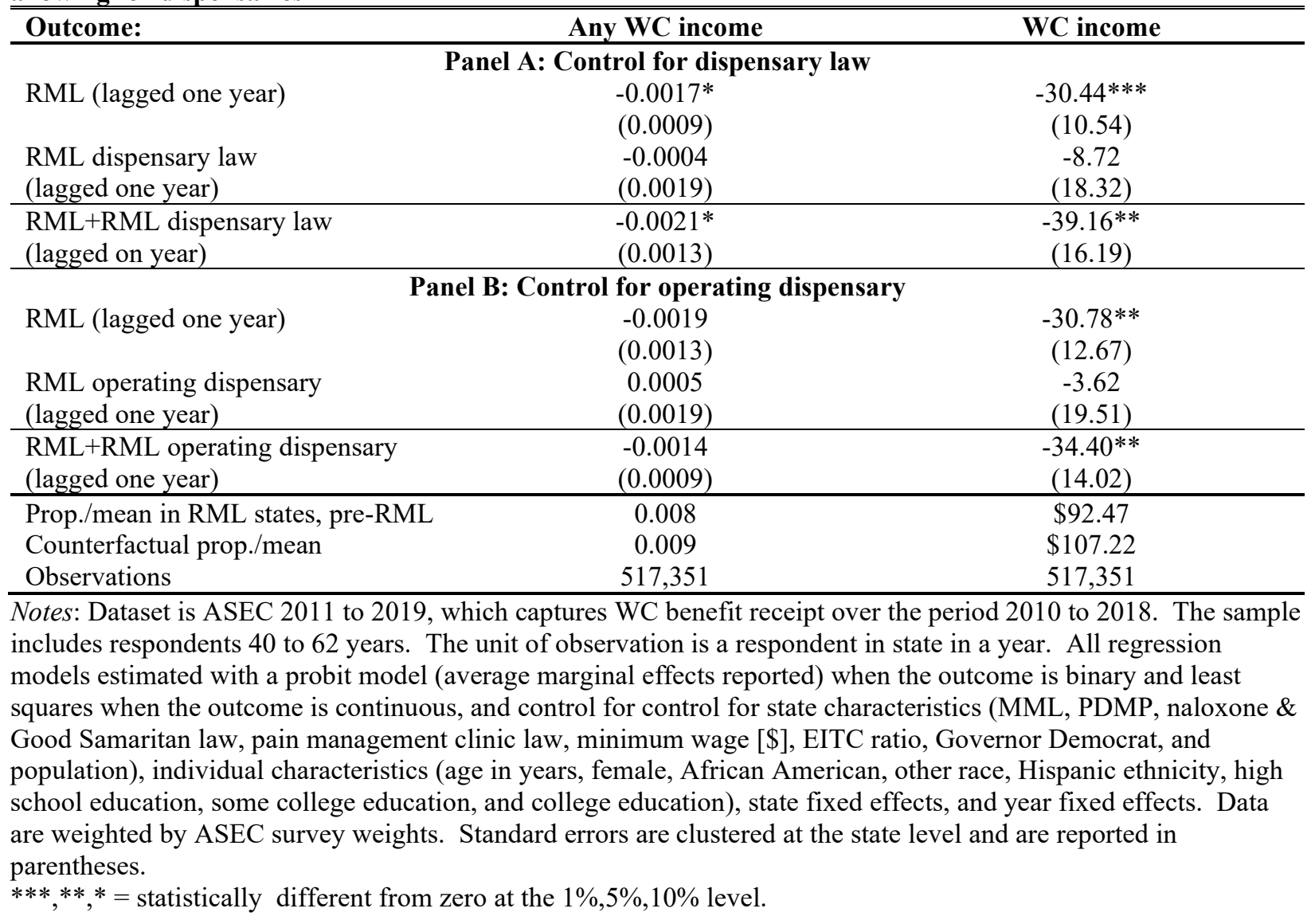


Appendix Table 7. Effect of recreational marijuana law passage on Workers' Compensation benefit receipt, heterogeneity by job physicality

\begin{tabular}{lcc}
\hline \hline Outcome: & Any WC income & WC income \\
\hline \multicolumn{3}{c}{ Panel A: Sample includes workers with a physically demanding job } \\
RML (lagged one year) & -0.0020 & -32.23 \\
& $(0.0017)$ & $(27.57)$ \\
\hline Prop./mean in RML states, pre-RML & 0.013 & $\$ 89.60$ \\
Counterfactual prop./mean & 0.015 & $\$ 102.45$ \\
Observations & 98,670 & 98,670 \\
\hline \multicolumn{3}{c}{ Panel B: Sample includes workers with a non-physically non-demanding job } \\
RML (lagged one year) & $-0.0016^{*}$ & -14.78 \\
& $(0.0008)$ & $(10.33)$ \\
\hline Prop./mean in RML states, pre-RML & 0.005 & $\$ 42.64$ \\
Counterfactual prop./mean & 0.006 & $\$ 50.47$ \\
Observations & 306,194 & 306,194 \\
\hline
\end{tabular}

Notes: The summation of the two sub-samples is less than the full sample due to missing information on job-type.

See text for job-type definitions and details. Dataset is ASEC 2011 to 2019, which captures WC benefit receipt over the period 2010 to 2018. The unit of observation is a respondent in state in a year. All regression models estimated with a probit model (average marginal effects reported) when the outcome is binary and least squares when the outcome is continuous, and control for state characteristics (MML, PDMP, naloxone \& Good Samaritan law, pain management clinic law, minimum wage [\$], EITC ratio, Governor Democrat, and population), individual characteristics (age in years, female, African American, other race, Hispanic ethnicity, high school education, some college education, and college education), state fixed effects, and year fixed effects. Data are weighted by ASEC survey weights. Standard errors are clustered at the state level and are reported in parentheses.

$* * *, * *, *=$ statistically different from zero at the $1 \%, 5 \%, 10 \%$ level. 
Appendix Table 8. Effect of recreational marijuana law passage on Workers' Compensation benefit receipt, heterogeneity by sex

\begin{tabular}{lcc}
\hline \hline Outcome: & Any WC income & WC income \\
\hline & Panel A: Men & \\
RML (lagged one year) & $-0.0020^{* *}$ & $-42.73^{*}$ \\
& $(0.0010)$ & $(23.13)$ \\
\hline Prop./mean in RML states, pre-RML & 0.0093 & $\$ 120.68$ \\
Counterfactual prop./mean & 0.0106 & $\$ 138.02$ \\
Observations & 249,623 & 249,623 \\
\hline & Panel B: Women & -22.01 \\
RML (lagged one year) & -0.0016 & $(16.47)$ \\
& $(0.0012)$ & $\$ 57.18$ \\
Prop./mean in RML states, pre-RML & 0.0061 & $\$ 77.78$ \\
Counterfactual prop./mean & 0.0073 & 267,728 \\
Observations & 267,728 & $2010.2018 .7 \mathrm{~T}$
\end{tabular}

Notes: Dataset is ASEC 2011 to 2019, which captures WC benefit receipt over the period 2010 to 2018. The unit of observation is a respondent in state in a year. All regression models estimated with a probit model (average marginal effects reported) when the outcome is binary and least squares when the outcome is continuous, and control for state characteristics (MML, PDMP, naloxone \& Good Samaritan law, pain management clinic law, minimum wage [\$], EITC ratio, Governor Democrat, and population), individual characteristics (age in years, female, African American, other race, Hispanic ethnicity, high school education, some college education, and college education), state fixed effects, and year fixed effects. Data are weighted by ASEC survey weights. Standard errors are clustered at the state level and are reported in parentheses.

$* * *, * *, *=$ statistically different from zero at the $1 \%, 5 \%, 10 \%$ level. 
Appendix Table 9. Effect of recreational marijuana law passage on SSDI and SSI benefit receipt

\begin{tabular}{lcc}
\hline & Panel A: SSDI outcomes & SSDI income \\
\hline Outcome: & Any SSDI income & -38.49 \\
RML (lagged one year) & $-0.0030^{* *}$ & $(32.29)$ \\
& $(0.001)$ & $\$ 213.00$ \\
\hline Prop./mean RML states, pre-RML & 0.014 & $\$ 219.76$ \\
Counterfactual prop./mean & 0.014 & 517,351 \\
Observations & 517,351 & SSI income \\
\hline & Panel B: SSI outcomes & -10.87 \\
\hline Outcome: & Any SSI income & $(15.66)$ \\
RML (lagged one year) & -0.0011 & $\$ 267.40$ \\
& $(0.002)$ & $\$ 257.10$ \\
\hline Prop./mean RML states, pre-RML & 0.028 & 517,351 \\
Counterfactual prop./mean & 0.027 & 517,351 \\
Observations & 5
\end{tabular}

Notes: Dataset is ASEC 2011 to 2019, which captures benefit receipt over the period 2010 to 2018. The sample includes respondents 40 to 62 years. The unit of observation is a respondent in state in a year. The any SSDI and any SSI regressions are estimated with a probit model and average marginal effects are reported. The SSDI income and SSI income regressions are estimated with least squares. All regression models control for state characteristics (MML, PDMP, naloxone \& Good Samaritan law, pain management clinic law, minimum wage [\$], EITC ratio, Governor Democrat, and population), individual characteristics (age in years, female, African American, other race, Hispanic ethnicity, high school education, some college education, and college education), state fixed effects, and year fixed effects. Data are weighted by ASEC survey weights. Standard errors are clustered at the state level and are reported in parentheses.

$* * *, * *, *=$ statistically different from zero at the $1 \%, 5 \%, 10 \%$ level. 
Appendix Figure 1. Trends in Workers' Compensation benefit receipt in each year of the study period Panel A: Any WC income

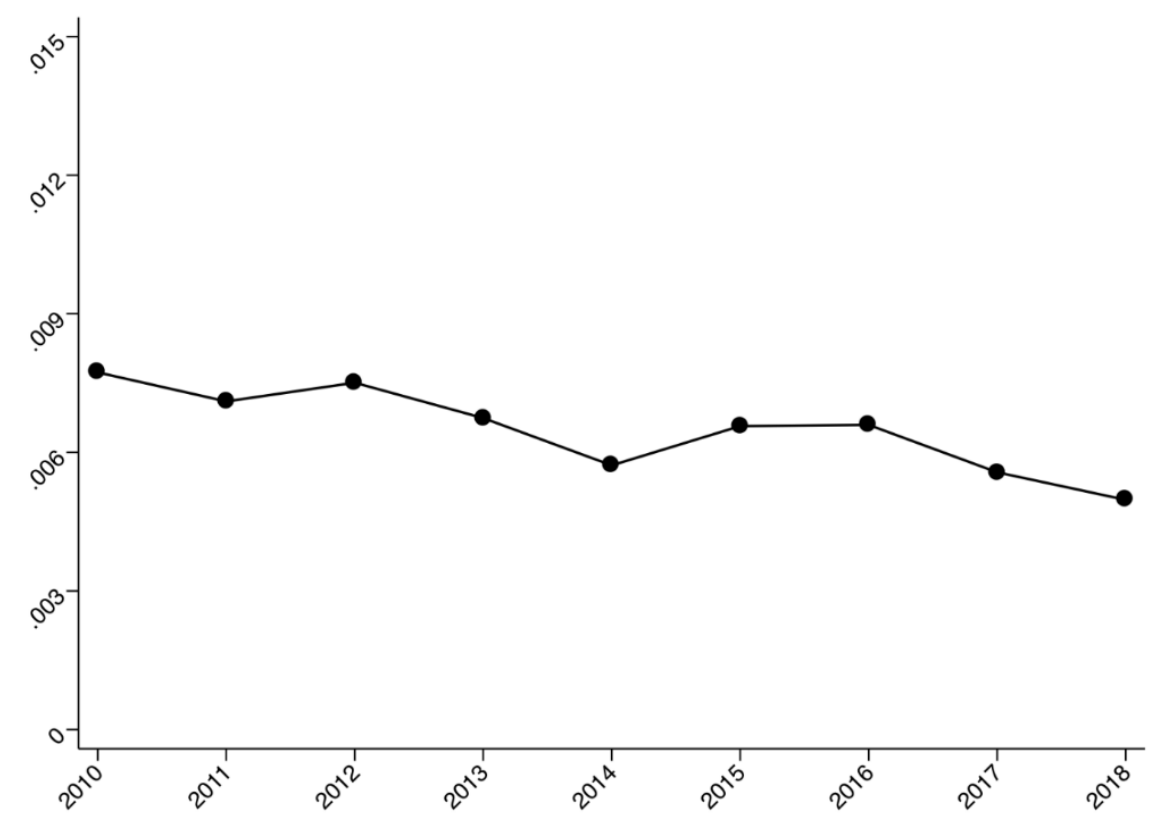

Panel B: WC income

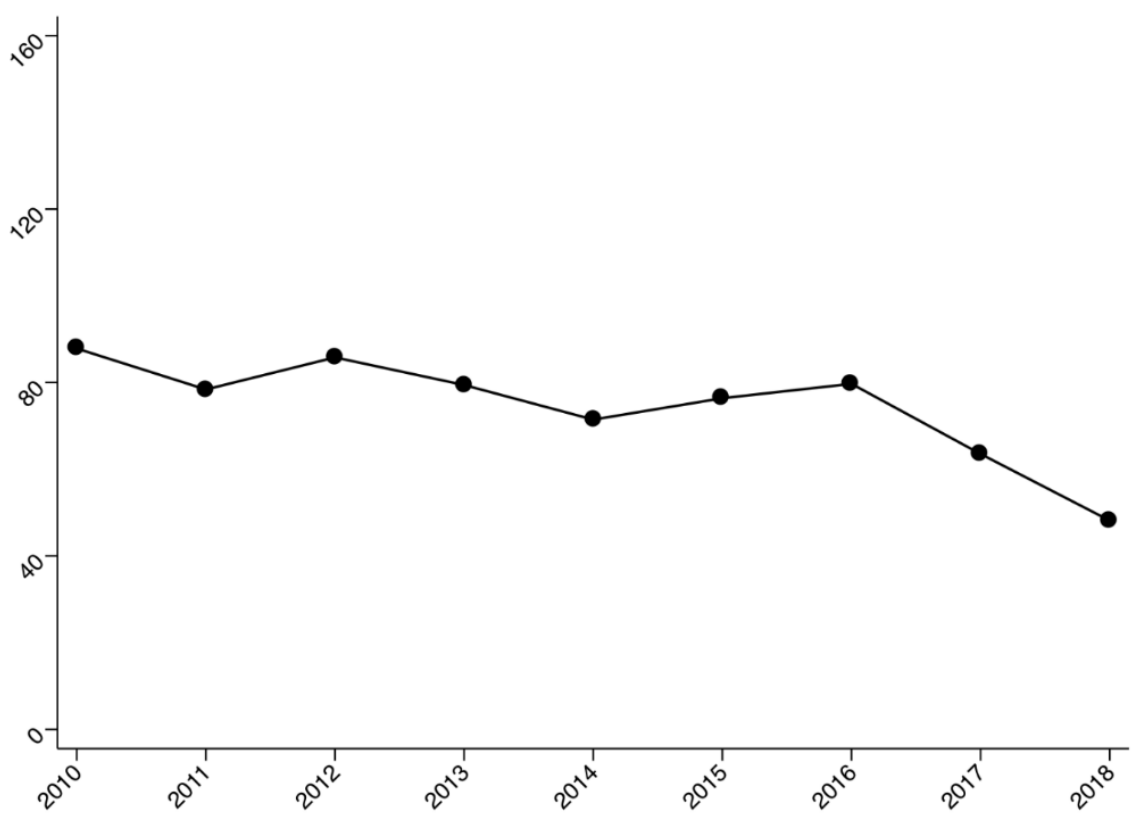

Notes: The data source is the ASEC 2011 to 2019, which captures WC benefit receipt over the period 2010 to 2018. The sample includes respondents 40 to 62 years. Data are aggregated to annual level and weighted by ASEC survey weights. 


\section{Appendix Figure 2. The effect of recreational marijuana law passage on Workers' Compensation benefit receipt: Leave-one-out analysis}

Panel A: Any WC income

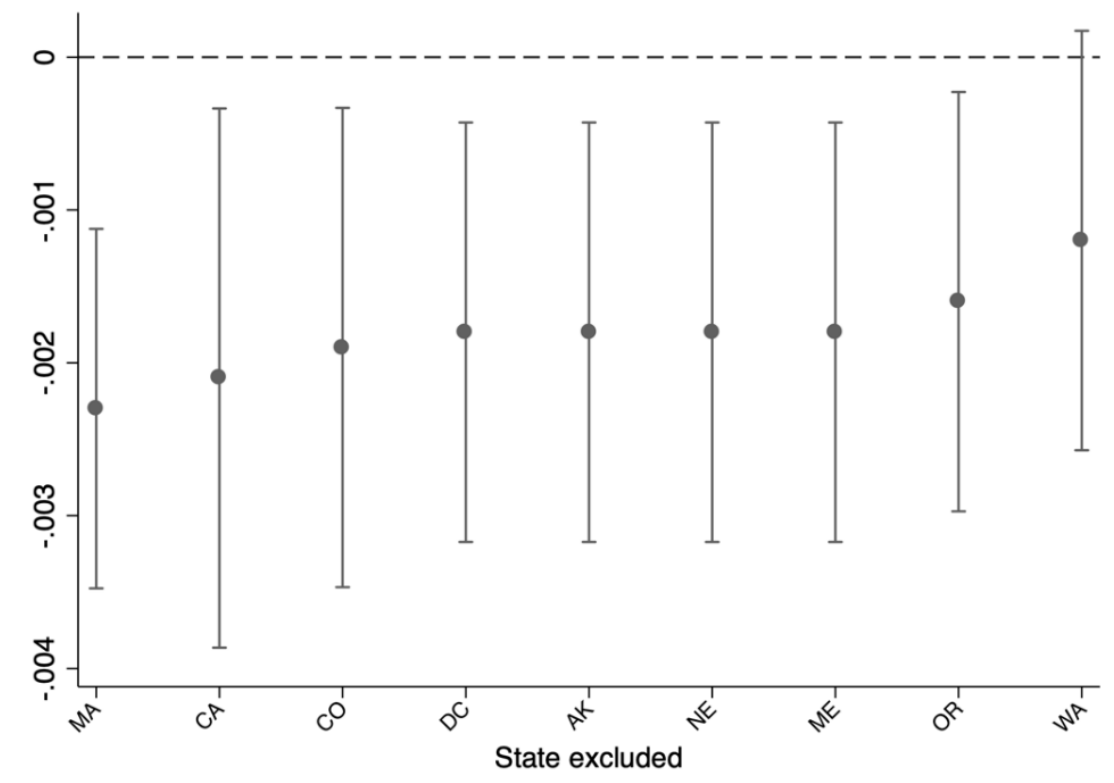

Panel B: WC income

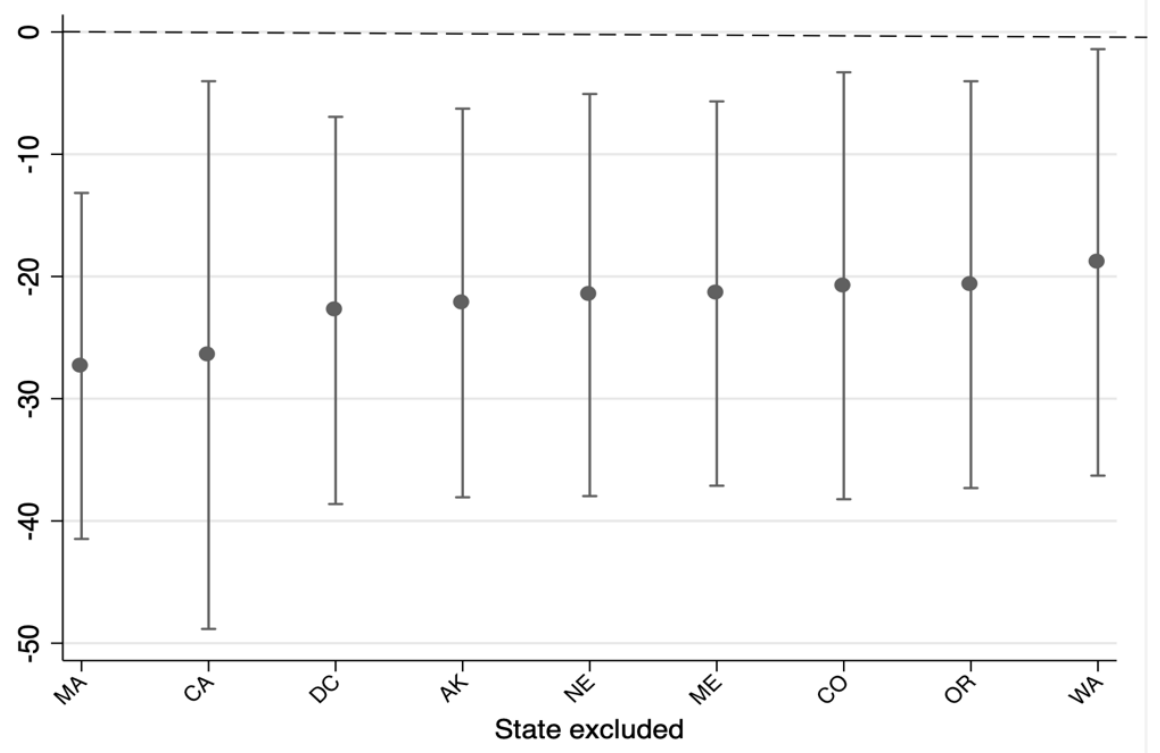

Notes: Dataset is ASEC 2011 to 2019, which captures WC benefit receipt over the period 2010 to 2018. The sample includes respondents 40 to 62 years. The unit of observation is a respondent in state in a year. Circles capture the coefficient estimate and vertical bars capture $95 \%$ confidence intervals that account for within-state clustering for each leave-one-out sample. All regression models estimated with a probit model (average marginal effects reported) when the outcome is binary and least squares when the outcome is continuous, and control for state characteristics (MML, PDMP, naloxone \& Good Samaritan law, pain management clinic law, minimum wage [\$], EITC ratio, Governor Democrat, and population), individual characteristics (age in years, female, African American, other race, Hispanic ethnicity, high school education, some college education, and college education), state fixed effects, and year fixed effects. Data are weighted by ASEC survey weights. 


\section{References:}

Abouk, R., and S. Adams. 2019. Legal cannabis access and the obesity of younger children. In University of Wisconsin-Milwakee Mimeo.

Ali, M.M., W.N. Dowd, T. Classen, R. Mutter, and S.P. Novak. 2017. "Prescription drug monitoring programs, nonmedical use of prescription drugs, and heroin use: Evidence from the national survey of drug use and health." Addictive Behaviors 69:65-77.

Altonji, J.G., T.E. Elder, and C.R. Taber. 2005. "Selection on observed and unobserved variables: Assessing the effectiveness of catholic schools." Journal of Political Economy 113 (1):151-184.

Anderson, D.M., D.I. Rees, and E. Tekin. 2018. "Medical marijuana laws and workplace fatalities in the united states." International Journal of Drug Policy 60:33-39.

Angrist, J.D., and J.-S. Pischke. 2008. Mostly harmless econometrics: An empiricist's companion: Princeton university press.

Bertrand, M., E. Duflo, and S. Mullainathan. 2004. "How much should we trust differences-indifferences estimates?" The Quarterly Journal of Economics 119 (1):249-275.

Bradford, A.C., and W.D. Bradford. 2016. "Medical marijuana laws reduce prescription medication use in medicare part d." Health Affairs 35 (7):1230-1236.

- 2017. "Medical marijuana laws may be associated with a decline in the number of prescriptions for medicaid enrollees." Health Affairs 36 (5):945-951.

Bronchetti, E.T. 2012. "Workers' compensation and consumption smoothing." Journal of Public Economics 96 (5-6):495-508.

Bronchetti, E.T., and M. McInerney. 2012. "Revisiting incentive effects in workers' compensation: Do higher benefits really induce more claims?" ILR Review 65 (2):286315. 2017. Does increased access to health insurance impact claims for workers' compensation? Evidence from massachusetts health care reform.

Bronchetti, E.T., and M.P. McInerney. 2019. "Health care reform and workers' compensation: Evidence from massachusetts." ILR Review.

Bureau of Labor Statistics. 2016. Nonfatal occupation injuries and illnesses requiring days away from work, 2015. Washington, DC: Bureau of Labor Statistics.

Bütikofer, A., C.J. Cronin, and M.M. Skira. 2020. "Employment effects of healthcare policy: Evidence from the 2007 fda black box warning on antidepressants." Journal of Health Economics 73:102348.

Bütikofer, A., and M.M. Skira. 2018. "Missing work is a pain: The effect of cox-2 inhibitors on sickness absence and disability pension receipt." Journal of Human Resources 53 (1):71122.

Cabral, M., C. Cui, and M. Dworsky. 2019. What is the rationale for an insurance coverage mandate? Evidence from workers' compensation insurance. In National Bureau of Economic Research Working Paper Series. Cambridge, MA: National Bureau of Economic Research.

Cabral, M., and M. Dillender. 2020. The impact of benefit generosity on workers' compensation claims: Evidence and implications. In National Bureau of Economic Research Working Paper Series. Cambridge, MA: National Bureau of Economic Research.

Carrieri, V., L. Madio, and F. Principe. 2020. "Do-it-yourself medicine? The impact of light cannabis liberalization on prescription drugs." Journal of Health Economics 74:102371. 
Cerdá, M., C. Mauro, A. Hamilton, N.S. Levy, J. Santaella-Tenorio, D. Hasin, M.M. Wall, K.M. Keyes, and S.S. Martins. 2020. "Association between recreational marijuana legalization in the united states and changes in marijuana use and cannabis use disorder from 2008 to 2016." JAMA Psychiatry 77 (2):165-171.

Cerdá, M., M. Wall, T. Feng, K.M. Keyes, A. Sarvet, J. Schulenberg, P.M. O’malley, R.L. Pacula, S. Galea, and D.S. Hasin. 2017. "Association of state recreational marijuana laws with adolescent marijuana use." JAMA Pediatrics 171 (2):142-149.

Chakraborty, A., J. Doremus, and S. Stith. 2020. The effects of recreational cannabis access on the labor market: Evidence from colorado.

Chan, N.W., J. Burkhardt, and M. Flyr. 2020. "The effects of recreational marijuana legalization and dispensing on opioid mortality." Economic Inquiry 58 (2):589-606.

Charles, K.K., M.S. Johnson, M. Stephens Jr, and D.Q. Lee. 2019. Demand conditions and worker safety: Evidence from price shocks in mining. National Bureau of Economic Research.

Chatterji, P. 2006. "Illicit drug use and educational attainment." Health Economics 15 (5):489511.

Choi, N.G., D.M. DiNitto, and C.N. Marti. 2017. "Nonmedical versus medical marijuana use among three age groups of adults: Associations with mental and physical health status." The American Journal on Addictions 26 (7):697-706.

Coe, N.B., and G. Zamarro. 2011. "Retirement effects on health in europe." Journal of Health Economics 30 (1):77-86.

Coile, C., K. Milligan, and D.A. Wise. 2017. "Health capacity to work at older ages: Evidence from the united states." In Social security programs and retirement around the world: The capacity to work at older ages, 359-394. University of Chicago Press.

Cutler, D.M., E. Meara, and S. Richards-Shubik. 2013. Health and work capacity of older adults: Estimates and implications for social security policy. Social Science Research Network.

Dahlhamer, J., J. Lucas, C. Zelaya, R. Nahin, S. Mackey, L. DeBar, R. Kerns, M. Von Korff, L. Porter, and C. Helmick. 2018. "Prevalence of chronic pain and high-impact chronic pain among adults — united states, 2016." Morbidity and Mortality Weekly Report 67 (36): 1001.

Daniller, A. 2019. Two-thirds of americans support marijuana legalization. In Fact tank: News in the numbers: Pew Research Center.

Dave, D., and S. Mukerjee. 2011. "Mental health parity legislation, cost-sharing and substanceabuse treatment admissions." Health Economics 20 (2):161-183.

de Chaisemartin, C., and X. d'Haultfœuille. 2020a. Difference-in-differences estimators of intertemporal treatment effects. In Social Science Research Network Working Paper Series: Social Science Research Network.

_. 2020b. "Two-way fixed effects estimators with heterogeneous treatment effects." American Economic Review 110 (9):2964-96.

Deyo, R.A., S.F. Dworkin, D. Amtmann, G. Andersson, D. Borenstein, E. Carragee, J. Carrino, R. Chou, K. Cook, and A. DeLitto. 2015. "Report of the nih task force on research standards for chronic low back pain." Physical Therapy 95 (2):e1-e18.

Dillender, M. 2015. "The effect of health insurance on workers' compensation filing: Evidence from the affordable care act's age-based threshold for dependent coverage." Journal of Health Economics 43:204-228. 
Dong, X. 2020. The economic impact of government regulations on marijuana and immigration. Ph.D., Syracuse University, Ann Arbor.

Dragone, D., G. Prarolo, P. Vanin, and G. Zanella. 2019. "Crime and the legalization of recreational marijuana." Journal of Economic Behavior \& Organization 159:488-501.

Dwyer, D.S., and O.S. Mitchell. 1999. "Health problems as determinants of retirement: Are selfrated measures endogenous?" Journal of Health Economics 18 (2):173-193.

Flood, S., M. King, S. Ruggles, and J.R. Warren. 2020. Integrated public use microdata series, current population survey. Minneapolis, MN: University of Minnesota.

Garthwaite, C.L. 2012. "The economic benefits of pharmaceutical innovations: The case of cox2 inhibitors." American Economic Journal: Applied Economics 4 (3):116-37.

Ghimire, K.M., and J.C. Maclean. 2020. "Medical marijuana and workers' compensation claiming." Health Economics 29 (4):419-434.

Gruber, J., and A.B. Krueger. 1991. "The incidence of mandated employer-provided insurance: Lessons from workers' compensation insurance." Tax Policy and the Economy 5:111-143.

Hales, C.M., C.B. Martin, and Q. Gu. 2020. Prevalence of prescription pain medication use among adults: United states, 2015-2018. In NCHS data brief Hyattsville, MD: National Center for Health Statistics.

Hansen, B., K. Miller, and C. Weber. 2020. "Early evidence on recreational marijuana legalization and traffic fatalities." Economic Inquiry 58 (2):547-568.

Hanson, K.L., J.L. Winward, A.D. Schweinsburg, K.L. Medina, S.A. Brown, and S.F. Tapert. 2010. "Longitudinal study of cognition among adolescent marijuana users over three weeks of abstinence." Addictive Behaviors 35 (11):970-976.

Hill, K.P. 2015. "Medical marijuana for treatment of chronic pain and other medical and psychiatric problems: A clinical review." JAMA 313 (24):2474-2483.

Hill, S.C., K.T. Solomon, J.C. Maclean, and M.F. Pesko. 2019. "Effects of improvements in the cps on the estimated prevalence of medical financial burdens." Health Services Research 54 (4):920-929.

Hirsch, B.T., D.A. Macpherson, and J.M. DuMond. 1997. "Workers compensation recipiency in union and nonunion workplaces." ILR Review 50 (2):213-236.

Hirth, R.A., M.E. Chernew, M.N. Turenne, M.V. Pauly, S.M. Orzol, and P.J. Held. 2003. "Chronic illness, treatment choice and workforce participation." International Journal of Health Care Finance and Economics 3 (3):167-181.

Hollingsworth, A., C. Wing, and A. Bradford. 2019. Comparative effects of recreational and medical marijuana laws on drug use among adult and adolescents. In Social Science Research Network Woking Paper Series: Social Science Research Network

Irons, J.G., K.A. Babson, C.L. Bergeria, and M.O. Bonn-Miller. 2014. "Physical activity and cannabis cessation." The American Journal on Addictions 23 (5):485-492.

Jinks, L., T.J. Kniesner, J. Leeth, and A.T. Lo Sasso. 2020. "Opting out of workers' compensation: Non-subscription in texas and its effects." Journal of Risk and Uncertainty 60 (1):53-76.

Kaestner, R., and M. Grossman. 1998. "The effect of drug use on workplace accidents." Labour Economics 5 (3):267-294.

Kasiser Family Foundation. 2021. Status of state medicaid expansion decisions. Washington, DC: Kasiser Family Foundation. 
Keeler, T.E., T.w. Hu, A. Keith, R. Manning, M.D. Marciniak, M. Ong, and H.Y. Sung. 2002. "The benefits of switching smoking cessation drugs to over-the-counter status." Health Economics 11 (5):389-402.

Kline, P., and A. Santos. 2012. "A score based approach to wild bootstrap inference." Journal of Econometric Methods 1 (1):23-41.

Kosiba, J.D., S.A. Maisto, and J.W. Ditre. 2019. "Patient-reported use of medical cannabis for pain, anxiety, and depression symptoms: Systematic review and meta-analysis." Social Science \& Medicine 233:181-192.

Krueger, A.B. 1990. "Incentive effects of workers' compensation insurance." Journal of Public Economics 41 (1):73-99.

Lakdawalla, D.N., R.T. Reville, and S.A. Seabury. 2007. "How does health insurance affect workers' compensation filing?" Economic Inquiry 45 (2):286-303.

Leigh, J.P. 2011. "Economic burden of occupational injury and illness in the united states." The Milbank Quarterly 89 (4):728-772.

Lopez-Garcia, I., N. Maestas, and K.J. Mullen. 2019. Latent work capacity and retirement expectations. In Stanford University mimeo.

Lynch, M.E., and F. Campbell. 2011. "Cannabinoids for treatment of chronic non-cancer pain; a systematic review of randomized trials." British Journal of Clinical Pharmacology 72 (5):735-744.

Macdonald, S., W. Hall, P. Roman, T. Stockwell, M. Coghlan, and S. Nesvaag. 2010. "Testing for cannabis in the work-place: A review of the evidence." Addiction 105 (3):408-416.

MacKinnon, J.G., and M.D. Webb. 2020. "Randomization inference for difference-in-differences with few treated clusters." Journal of Econometrics.

Maclean, J.C., K.M. Ghimire, and L. Nicholas. 2020. "Marijuana legalization and disability claiming." Health Economics Forthcoming.

Maclean, J.C., and B. Saloner. 2018. "Substance use treatment provider behavior and healthcare reform: Evidence from massachusetts." Health Economics 27 (1):76-101.

McMichael, B.J., R.L. Van Horn, and W.K. Viscusi. 2020. "The impact of cannabis access laws on opioid prescribing." Journal of Health Economics 69:102273.

Meyer, B.D., W.K. Viscusi, and D.L. Durbin. 1995. "Workers' compensation and injury duration: Evidence from a natural experiment." The American Economic Review:322340 .

Moffitt, R. 1992. "Incentive effects of the us welfare system: A review." Journal of Economic Literature 30 (1):1-61.

National Academies of Sciences, E., and Medicine. 2017. The health effects of cannabis and cannabinoids: The current state of evidence and recommendations for research: National Academies Press.

National Institute on Drug Abuse. 2020. How does marijuana use affect school, work, and social life? Bethesda, MD: National Institute on Drug Abuse.

Neuhauser, F., and S. Raphael. 2004. "The effect of an increase in worker's compensation benefits on the duration and frequency of benefit receipt." Review of Economics and Statistics 86 (1):288-302.

Nicholas, L.H., and J.C. Maclean. 2019. "The effect of medical marijuana laws on the health and labor supply of older adults: Evidence from the health and retirement study." Journal of Policy Analysis and Management 38 (2):455-480. 
O'Leary, P., L.I. Boden, S.A. Seabury, and A. Ozonoff. 2012. "Workplace injuries and the takeup of social security disability benefits." Soc. Sec. Bull. 72:1.

Ohsfeldt, R.L., and M.A. Morrisey. 1997. "Beer taxes, workers' compensation, and industrial injury." Review of Economics and Statistics 79 (1):155-160.

Park, J.-Y., and L.-T. Wu. 2017. "Prevalence, reasons, perceived effects, and correlates of medical marijuana use: A review." Drug and Alcohol Dependence 177:1-13.

Prescription Drug Abuse Policy System. 2020. Prescription drug abuse policy system.

ProCon.org. 2020a. Legal medical marijuana states and dc. ProCon.org.

- 2020b. Legal recreational marijuana states and dc. ProCon.org.

Register, C.A., and D.R. Williams. 1992. "Labor market effects of marijuana and cocaine use among young men." ILR Review 45 (3):435-448.

Reinarman, C., H. Nunberg, F. Lanthier, and T. Heddleston. 2011. "Who are medical marijuana patients? Population characteristics from nine california assessment clinics." Journal of Psychoactive Drugs 43 (2):128-135.

Roodman, D., M.Ø. Nielsen, J.G. MacKinnon, and M.D. Webb. 2019. "Fast and wild: Bootstrap inference in stata using boottest." The Stata Journal 19 (1):4-60.

Sabia, J.J., and T.T. Nguyen. 2018. "The effect of medical marijuana laws on labor market outcomes." The Journal of Law and Economics 61 (3):361-396.

Schmidheiny, K., and S. Siegloch. 2020. On event studies and distributed-lags in two-way fixed effects models: Identification, equivalence, and generalization. In $Z E W$-Centre for European Economic Research Discussion Paper.

Summers, L.H. 1989. "Some simple economics of mandated benefits." The American Economic Review 79 (2): 177-183.

Thirumurthy, H., J.G. Zivin, and M. Goldstein. 2008. "The economic impact of aids treatment labor supply in western kenya." Journal of Human Resources 43 (3):511-552.

U.S. Department of Labor. 2016. Does the workers' compensation system fulfill its obligations to injured workers? Washington, DC: U.S. Department of Labor.

Ullman, D.F. 2017. "The effect of medical marijuana on sickness absence." Health Economics 26 (10):1322-1327.

University of Kentucky Center for Poverty Research. 2020. State level data of economic, political, and transfer program information for 1980-2018. Lexington, KY: University of Kentucky.

Van Ours, J.C., and J. Williams. 2012. "The effects of cannabis use on physical and mental health." Journal of Health Economics 31 (4):564-577.

Van Ours, J.C., J. Williams, D. Fergusson, and L.J. Horwood. 2013. "Cannabis use and suicidal ideation." Journal of Health Economics 32 (3):524-537.

Volkow, N.D., R.D. Baler, W.M. Compton, and S.R. Weiss. 2014. "Adverse health effects of marijuana use." New England Journal of Medicine 370 (23):2219-2227.

Watson, S.J., J.A. Benson, and J.E. Joy. 2000. "Marijuana and medicine: Assessing the science base: A summary of the 1999 institute of medicine report." Archives of General Psychiatry 57 (6):547-552.

Weiss, E., G. Murphy, and L.I. Boden. 2020. Workers' compensation benefits, costs, and coverage - 2018 data. Washington, DC: National Academy of Social Insurance.

Wen, H., and J.M. Hockenberry. 2018. "Association of medical and adult-use marijuana laws with opioid prescribing for medicaid enrollees." JAMA Internal Medicine 178 (5):673679. 
Whiting, P.F., R.F. Wolff, S. Deshpande, M. Di Nisio, S. Duffy, A.V. Hernandez, J.C. Keurentjes, S. Lang, K. Misso, and S. Ryder. 2015. "Cannabinoids for medical use: A systematic review and meta-analysis." JAMA 313 (24):2456-2473.

Williams, J., and J.C. van Ours. 2020. "Hazardous or not? Cannabis use and early labor market experiences of young men." Health Economics 29 (10):1148-1160.

Winward, J.L., K.L. Hanson, S.F. Tapert, and S.A. Brown. 2014. "Heavy alcohol use, marijuana use, and concomitant use by adolescents are associated with unique and shared cognitive decrements." Journal of the International Neuropsychological Society: JINS 20 (8):784.

Zwerling, C., J. Ryan, and E.J. Orav. 1990. "The efficacy of preemployment drug screening for marijuana and cocaine in predicting employment outcome." JAMA 264 (20):2639-2643. 